\title{
Mycobacterial hypersensitivity pneumonitis requires TLR9-MyD88 in lung CD11b+ CD11c+ cells
}

\author{
H. Daito*,**, T. Kikuchi",**, T. Sakakibara\# ${ }^{*}$ K. Gomi ${ }^{\#}$, T. Damayanti*, J. Zaini*, \\ N. Tode*, M. Kanehira*, S. Koyama*, S. Fujimura", M. Ebina ${ }^{\star *}$, K.J. Ishii ${ }^{+}$, S. Akira ${ }^{\S}$, \\ T. Takai ${ }^{f}$, A. Watanabe ${ }^{\#, \oplus}$ and T. Nukiwa*,\#
}

ABSTRACT: Mycobacteria are among the most common causes of hypersensitivity pneumonitis (HP), but controversy persists with regard to the involvement of the infectious potency of the organism in mycobacterial HP (hot tub lung). This study aimed to establish a mouse model of hot tub lung to clarify its pathophysiology.

Mice were exposed intranasally to formalin-killed Mycobacterium avium from a patient with hot tub lung (HP strain) or chronic pulmonary infection (non-HP strain), and bronchoalveolar lavage fluids and lung tissues were evaluated for allergic inflammation.

Dead $M$. avium HP strain, but not non-HP strain, elicited marked HP-like pulmonary inflammation in wild-type mice. Although the inflammation was induced in mice lacking CD4 or CD8, the induction of HP-like responses was prevented in mice lacking myeloid differentiation factor (MyD)88 or Toll-like receptor (TLR)9. Cultured lung CD11C+ cells responded to $M$. avium in a TLR9-dependent manner, and reconstitution of TLR9-/- mice with lung CD11C+ cells from wildtype mice restored the inflammatory responses. Further investigation revealed that pulmonary exposure to $M$. avium HP strain increased the number of lung CD11b+CD11c+ cells (dendritic cells) through TLR9 signalling.

Our results provide evidence that hot tub lung develops via the mycobacterial engagement of TLR9-MyD88 signalling in lung CD11b+ dendritic cells independent of the mycobacterial infectious capacity.

KEYWORDS: Dendritic cells, hypersensitivity pneumonitis, innate immunity, nontuberculous mycobacteria, Toll-like receptors

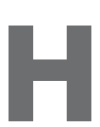
ypersensitivity pneumonitis (HP), also known as extrinsic allergic alveolitis, is a granulomatous inflammatory lung disease that represents an immunological response to inhalation of airborne aetiological agents [1-3]. Over 300 agents have been reported as causative, but avian antigens, mycobacteria associated with hot tubs and organic dust derived from farming practices account for most cases of HP with identifiable causes [1-4]. Despite the limited range of aetiological agents, the underlying pathophysiology of HP remains ill-defined, and therefore no specific laboratory tests are available to make a definite diagnosis of HP easily [1-3, 5].

There is considerable debate regarding the pathogenesis of hot tub lung, a major clinical form of HP caused by pulmonary exposure to nontuberculous mycobacteria, mainly Mycobacterium avium, present in hot water aerosols from hot tubs, whirlpools and spas [6, 7]. Mycobacteria have pathogenic potential not only as immunogenic agents for HP, but also as infectious agents for chronic pulmonary infections even in immunocompetent subjects [8-12]. Such epidemiological features of mycobacteria raise unresolved questions about hot tub lung disease, i.e. whether an inflammatory process, an infectious process or a combination of both contributes to the disease process, and whether mycobacterial agents, other hot tub cofactors or host predisposition is responsible for the pathogenesis $[9,12]$. Although an animal model of HP disease in response to the inhalation of mycobacteria would be likely to

\section{AFFILIATIONS}

*Dept of Pulmonary Medicine,

Tohoku University Graduate School of Medicine,

"Research Division for Development of Anti-Infective Agents, Institute of Development, Ageing and Cancer, and,

${ }^{f}$ Dept of Experimental Immunology, Institute of Development, Ageing and Cancer, Tohoku University,

\#Dept of Pulmonary Medicine,

Tohoku University Hospital, Sendai, +Laboratory of Vaccine Science, and ${ }^{\S}$ Laboratory of Host Defense, WPI Immunology Frontier Research Center, Osaka University, Osaka, Japan.

${ }^{* *}$ These authors contributed equally to this work.

CORRESPONDENCE

T. Kikuchi

Dept of Pulmonary Medicine

Tohoku University Hospital

1-1 Seiryomachi

Aobaku

Sendai $980-8574$

Japan

E-mail: kikuchi@idac.tohoku.ac.jp

Received:

Nov 162010

Accepted after revision:

Jan 062011

First published online:

Jan 272011

European Respiratory Journal

Print ISSN 0903-1936

Online ISSN 1399-3003 
resolve these controversies, no animal model of hot tub lung has yet been reported.

The primary objective of this study was to establish a mouse model of hot tub lung with a clinical isolate of M. avium from a patient with hot tub lung disease, referred to as M. avium $\mathrm{HP}$ strain. The participation of either inflammatory or infectious processes in the pathogenesis of hot tub lung disease was delineated using formalin-killed mycobacteria. We also focused on the immunopathology of hot tub lung disease using mice deficient in several immunological molecules that are essential for innate and adaptive immune systems.

\section{METHODS}

Mice

C57BL/6 mice were purchased from Charles River Japan (Yokohama, Japan). CD4-deficient (B6.129S2-Cd4 ${ }^{\text {tm1Mak }} / \mathrm{J}$ ) and CD8-deficient (B6.129S2-Cd8a $\left.a^{t m 1 M a k} / \mathrm{J}\right)$ mice were obtained from Jackson Laboratory (Bar Harbor, ME, USA). Toll/ interleukin (IL)-1 receptor domain-containing adaptor inducing interferon (IFN)- $\beta$ (TRIF)-deficient mice were generated as described previously and were backcrossed to C57BL/6 [13]. Myeloid differentiation factor (MyD)88-, Toll-like receptor (TLR)2-, TLR4-, TLR7- and TLR9-deficient mice were purchased from Oriental BioService (Kyoto, Japan). All animals used in this study were matched for age (6-10 weeks old), sex (female) and strain (C57BL/6 background) within each experiment, and were housed under specific pathogen-free conditions, in accordance with the guidelines of the institutional animal care and use committee of our institution.

\section{Mycobacterium avium strains}

The $M$. avium strains used in this study were two clinical isolates, HP and non-HP strains. The HP and non-HP strains were isolated from sputum specimens of a patient with hot tub lung disease and a patient with chronic pulmonary infection, respectively. The $M$. avium isolates were grown in Middlebrook 7H9 broth with ADC enrichment medium (BD Diagnostics, Sparks, MD, USA) for $2-3$ weeks at $37^{\circ} \mathrm{C}$ under $5 \% \quad \mathrm{CO}_{2}$. Formalin-killed ( $2 \%$ for $1 \mathrm{~h}$ ) M. avium was washed three times and suspended in sterile PBS (pH 7.4). The concentration was adjusted spectrophotometrically. Mycobacterial killing was confirmed by incubating $10^{9} \mathrm{CFU}$ of formalin-killed $M$. avium on 7H10 agar plates containing OADC enrichment medium (BD Diagnostics) at $37^{\circ} \mathrm{C}$ under $5 \% \mathrm{CO}_{2}$ for 3 weeks with no consequent colony formation. PCR-based mycobacterial genotyping with variable numbers of tandem repeats (VNTR) was essentially as described previously, and the number of repeat units was determined in four repetitive unit loci using the following primer sets: Mycobacterium avium tandem repeats (MATR)-1, 5'-GAACGTTGGGCCGAATGCGA-3' and 5'-GTG TCGGACCCCTCCCGTAA-3'; MATR-2, 5' ${ }^{\prime}$-TTGAGCAGCTC GTAAAGCGT-3' and 5'-CGCGCTCAAGGAGATGGTTC-3'; MATR-3, 5'-TCCTCGACAATCAGCACACT-3' and 5'-CCAA TCACAACGGCACCATC-3'; MATR-4, 5'-TCGTTCTGGTGGC CTTCGGT-3' and 5'-TGTCCAGGTGGAGTTTTCGC-3' [14].

\section{Exposure protocols}

We carried out intranasal administration of $2 \times 10^{8} \mathrm{CFU}$ of formalin-killed $M$. avium $(50 \mu \mathrm{L})$ into anaesthetised mice on three consecutive days per week for 3 weeks or on only two consecutive days. 4 or 5 days after the last exposure, bronchoalveolar lavage (BAL) fluid and lungs were obtained from the mice as described previously $[15,16]$. Briefly, the lungs were lavaged twice with $0.75 \mathrm{~mL}$ PBS. After centrifugation $(2,300 \times g$ for $5 \mathrm{~min})$, the supernatants were used to determine the concentrations of IL-4, IL-12p40, tumour necrosis factor (TNF)- $\alpha$, and IFN- $\gamma$ with ELISA kits (Invitrogen, Carlsbad, CA). After the cell pellets were resuspended in $1 \mathrm{~mL}$ PBS, total BAL cells were counted with a haemocytometer, and $\geqslant 300$ cells on cytospin slides stained with Diff-Quik (Sysmex, Kobe, Japan) were differentiated on the basis of cellular morphology and staining characteristics of macrophages, lymphocytes, neutrophils, and eosinophils. Paraffin sections ( $5 \mu \mathrm{m}$ thick) were prepared from lung tissue fixed with $10 \%$ formaldehyde, and were stained with haematoxylin and eosin for histological assessment.

\section{Isolation of lung CD11c+ cells for cytokine assay and cell transfer}

Single-lung cell suspensions were prepared by collagenase digestion and red blood cell lysis, and CD11c+ and CD11ccells were purified with magnetically labelled beads specific for mouse CD11c (Miltenyi Biotec, Auburn, CA, USA). The cell purity was typically $>85 \%$ as assessed by staining cells with fluorescein isothiocyanate (FITC)-conjugated anti-CD11c antibody (clone HL3; BD Biosciences). IL-12p40 secretion in vitro was determined in cell supernatants using a commercial ELISA kit as described above, after the lung CD11c+ and CD11c- cells $\left(10^{5}\right.$ per well) were cultured with $10^{7} \mathrm{CFU}$ of formalin-killed $M$. avium HP strain or $5 \mu \mathrm{g} \cdot \mathrm{mL}^{-1}$ synthetic cytidine-phosphate-guanosine (CpG) oligodeoxynucleotides (endotoxin <0.001 U. $\mathrm{mg}^{-1}$; GeneDesign, Osaka, Japan) in complete RPMI-1640 media (10\% fetal bovine serum, $2 \mathrm{mM}$ L-glutamine, $100 \mathrm{U} \cdot \mathrm{mL}^{-1}$ penicillin, and $100 \mu \mathrm{g} \cdot \mathrm{mL}^{-1}$ streptomycin) for $24 \mathrm{~h}$ [17]. In the cell transfer experiments, $10^{6}$ lung CD11c+ or CD11c- cells were intravenously transferred into TLR9-deficient mice 1 day before exposure to the formalinkilled M. avium HP strain.

\section{Flow cytometry}

Surface phenotype of lung CD11c+ cells was analysed for CD11b and CD103 expression as previously described [18-20]. After counting, lung CD11c+ cells magnetically purified as described above were stained with FITC-conjugated anti-CD103 (clone M290; BD Biosciences) and phycoerythrin (PE)-conjugated anti-CD11b antibody (clone M1/70; BD Biosciences) [21]. To detect plasmacytoid dendritic cells (DCs), lung cells were stained with PE-conjugated anti-mouse plasmacytoid dendritic cell antigen-1 (mPDCA-1) antibody (clone JF05-1C2.4.1; Miltenyi Biotec). The expression of surface markers was analysed using an EPICS XL cytometer with EXPO32 ADC software (Beckman Coulter, Fullerton, CA, USA).

\section{Statistical analysis}

All data are reported as mean \pm SE. Statistical comparisons were performed by using the two-tailed (unpaired) t-test. In all analyses, p-values $<0.05$ were taken to indicate statistical significance.

\section{RESULTS}

\section{Patient with hot tub lung}

A 66-yr-old man was referred to our hospital due to a 1-month history of cough, weight loss and exertional dyspnoea. He had 


\begin{tabular}{|c|c|}
\hline \multicolumn{2}{|l|}{ Haematology } \\
\hline White blood cells $\mu \mathrm{L}^{-1}$ & 7000 \\
\hline Red blood cells $\mu \mathrm{L}^{-1}$ & $4.39 \times 10^{5}$ \\
\hline Haemoglobin $\mathrm{g} \cdot \mathrm{dL}^{-1}$ & 13.5 \\
\hline Platelets $\mu \mathrm{L}^{-1}$ & $23.3 \times 10^{6}$ \\
\hline \multicolumn{2}{|l|}{ Serology } \\
\hline C-reactive protein $\mathrm{mg} \cdot \mathrm{dL}^{-1}$ & 0.1 \\
\hline $\mathrm{KL}-6 \mathrm{U} \cdot \mathrm{mL}^{-1}$ & 1090 \\
\hline \multicolumn{2}{|l|}{ Blood gas analysis (room air) } \\
\hline $\mathrm{pH}$ & 7.45 \\
\hline $\mathrm{Pa}, \mathrm{CO}_{2}$ Torr & 37.3 \\
\hline $\mathrm{Pa}, \mathrm{O}_{2}$ Torr & 76.8 \\
\hline $\mathrm{HCO}_{3}^{-} \mathrm{mmol} \cdot \mathrm{L}^{-1}$ & 25.6 \\
\hline \multicolumn{2}{|l|}{ Biochemistry } \\
\hline Total protein $\mathrm{g} \cdot \mathrm{dL}^{-1}$ & 7.1 \\
\hline Albumin $\mathrm{g} \cdot \mathrm{dL}^{-1}$ & 3.9 \\
\hline Aspartate aminotransferase $\mathrm{IU} \cdot \mathrm{L}^{-1}$ & 23 \\
\hline Alanine aminotransferase $\mathrm{IU} \cdot \mathrm{L}^{-1}$ & 20 \\
\hline Lactate dehydrogenase IU. $\mathrm{L}^{-1}$ & 172 \\
\hline Blood urea nitrogen $\mathrm{mg} \cdot \mathrm{dL}^{-1}$ & 19 \\
\hline Creatinine $\mathrm{mg} \cdot \mathrm{dL}^{-1}$ & 1.0 \\
\hline Sodium $\mathrm{mEq} \cdot \mathrm{L}^{-1}$ & 142 \\
\hline Potassium $\mathrm{mEq} \cdot \mathrm{L}^{-1}$ & 3.7 \\
\hline Chloride $\mathrm{mEq} \cdot \mathrm{L}^{-1}$ & 106 \\
\hline Trichosporon cutaneum antibody & Negative \\
\hline \multicolumn{2}{|l|}{ BAL fluid } \\
\hline Recovery rate \% & 56 \\
\hline Total cells $\mathrm{mL}^{-1}$ & $7.4 \times 10^{5}$ \\
\hline Macrophages \% & 48 \\
\hline Neutrophils \% & 1 \\
\hline Lymphocytes \% & 51 \\
\hline Eosinophils \% & 0 \\
\hline $\mathrm{CD} 4 / \mathrm{CD} 8$ & 18.2 \\
\hline \multicolumn{2}{|l|}{ Sputum } \\
\hline Acid-fast bacilli & Positive \\
\hline Mycobacterium avium-PCR & Positive \\
\hline Culture & Mycobacterium avium \\
\hline Cytology & Class II \\
\hline
\end{tabular}

$\mathrm{Pa}_{1} \mathrm{CO}_{2}$ : arterial carbon dioxide tension; $\mathrm{Pa}_{1} \mathrm{O}_{2}$ : arterial oxygen tension; $\mathrm{BAL}$ : bronchoalveolar lavage fluid.

no significant past medical history and had never smoked. At the time of admission to our hospital, bilateral pulmonary fine crackles were heard on auscultation. He was slightly hypoxaemic (arterial oxygen tension 76.8 Torr; table 1). The results of pulmonary function test were normal. Chest radiography showed bilateral military nodules and opacities, with lower lobe predominance (fig. 1a). Computed tomography (CT) scan of the chest revealed diffuse ground-glass opacities accompanied by ill-defined centrilobular micronodules (fig. $1 \mathrm{~b}$; see online supplement for an enlarged version). Transbronchial lung biopsy exhibited non-necrotising granulomas, with multinucleated giant cells in a peribronchial distribution (fig. 1c). BAL yielded $7.4 \times 10^{5}$ cells $\cdot \mathrm{mL}^{-1}, 51 \%$ of which were lymphocytes (table 1). Chest images as well as lung biopsy and BAL specimens were regarded as compatible with $\mathrm{HP}$, despite the lack of detectable antibody against Trichosporon cutaneum, which may cause Japanese summer-type HP [1-4, 22]. The sputum was positive for acid-fast bacilli, and M. avium was cultured from the patient's sputum and BAL fluid samples. By home environmental sampling, the drain in the patient's bathroom was found to contain heavy growth of M. avium, which was identical to that in sputum as determined by VNTR analysis (fig. 1d). Based on this constellation of findings, we made a diagnosis of HP due to inhalation of M. avium in the patient's bathroom at home (i.e. hot tub lung), which he was advised to renovate. He discontinued use of the contaminated bathroom, and within 5 months, he showed clinical improvement with complete resolution of findings on CT scan without any medication (fig. 1e, see online supplement for an enlarged version).

\section{HP-like reactions induced by pulmonary exposure to $\mathrm{M}$. avium from the patient with hot tub lung}

We assumed that the pathological features of hot tub lung disease are dependent on the immunogenicity of inhaled $M$. avium. This hypothesis was supported by an animal model in which mice were exposed intranasally to killed $M$. avium on three consecutive days per week for 3 weeks (fig. 2). We used $M$. avium isolated from the sputum of the patient with hot tub lung disease, referred to as the HP strain, which had been killed by formalin treatment, for repeated intranasal instillation to separate the infectious potency from the pathogenicity (fig. 2a). The killed M. avium HP strain induced HP-like cellular responses in the BAL fluid, with significantly increased numbers of total cells, neutrophils and lymphocytes, but not of macrophages or eosinophils, compared with those in the BAL fluid of mice exposed to killed $M$. avium from a patient with chronic pulmonary infection, referred to as the non-HP strain (total cells, $\mathrm{p}<0.05$; neutrophils, $\mathrm{p}<0.01$; lymphocytes, $\mathrm{p}<0.05$; macrophages, $p>0.05$; eosinophils, $p>0.05$; fig. $2 b$ and data not shown). The BAL fluid of wild-type mice exposed to $M$. avium HP strain showed T-helper (Th)1-skewed cytokine responses with high levels of IL-12p40, TNF- $\alpha$, and IFN- $\gamma$, but not IL-4; these cytokine responses were compatible with those reported previously in clinical HP patients (M. avium HP versus non-HP strain; IL-12p40, $\mathrm{p}<0.01$; TNF- $\alpha, \mathrm{p}<0.05$; IFN- $\gamma, \mathrm{p}<0.01$; IL-4, $\mathrm{p}>0.05$; fig. $2 \mathrm{c}-\mathrm{e}$ and data not shown) [5]. The lungs of mice exposed to M. avium HP strain, but not non-HP strain, showed histopathological alterations consistent with $\mathrm{HP}$, including marked peribronchial and perivascular mononuclear cell infiltration, interstitial inflammation and non-necrotizing granulomas (fig. 2f). These data indicated that M. avium from the patient with hot tub lung disease provoked HP-like reactions via the immunostimulatory capacity of the mycobacteria, independent of the mycobacterial infectious capability.

\section{M. avium-induced HP-like reactions in the absence of CD4+ or CD8+ T-cells}

Although CD4+ Th1 cells and CD8+ cytotoxic T-cells, key effector cells of adaptive immunity, have been suggested to be important in the pathophysiology of HP, neither CD4 nor CD8 deficiency impaired the development of HP-like reactions in our mouse model of hot tub lung (fig. 3). Although wild-type mice exposed to killed M. avium HP strain exhibited increased numbers of total cells, neutrophils and lymphocytes with high levels of Th1-skewing cytokine production in the BAL fluid, there were no significant differences between CD4-/- or CD8-/mice and wild-type mice (total cells, $\mathrm{p}>0.05$; neutrophils, 

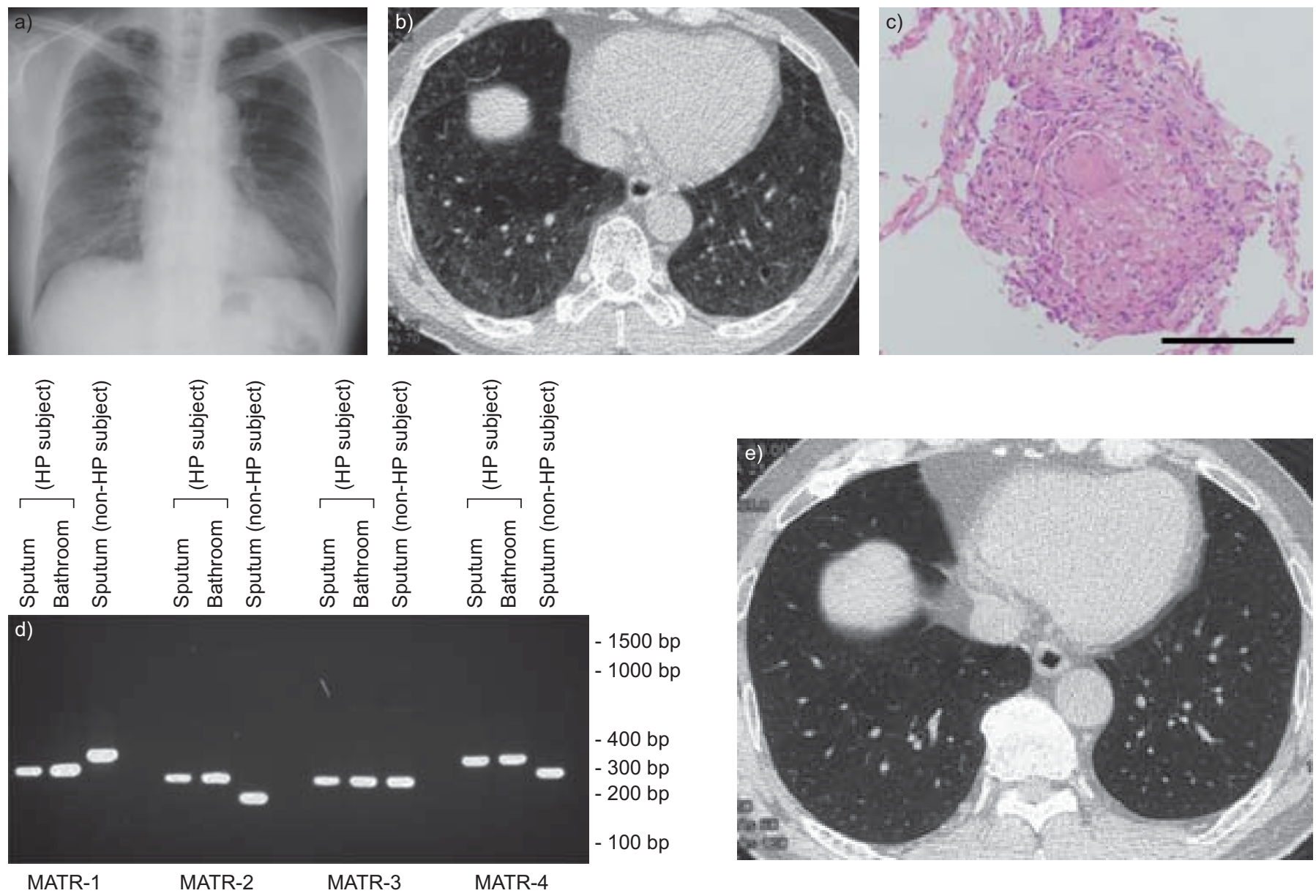

FIGURE 1. Clinical findings in a patient with hot tub lung disease. a) Chest radiograph on hospital admission. b) Chest computed tomography (CT) on hospital admission. c) Histological lung section stained with haematoxylin and eosin at $\times 100$ magnification. Scale bar $=200 \mu m$. d) Variable numbers of tandem repeats profiling of Mycobacterium avium isolates from the patient's sputum and the bathroom in his home (hypersensitivity pneumonitis (HP) subject). Controls included M. avium cultured from sputum from a subject with chronic pulmonary infection (non-HP subject). Four repetitive unit genomic loci (Mycobacterium avium tandem repeats (MATR)-1 to MATR-4) were amplified by PCR and electrophoresed on a 2.5\% agarose gel. e) Chest CT 5 months after the patient discontinued use of the bathroom in question.

$\mathrm{p}>0.05$; lymphocytes, $\mathrm{p}>0.05 ;$ IL-12p 40 , $\mathrm{p}>0.05$; TNF- $\alpha, \mathrm{p}>0.05$; IFN- $\gamma, \mathrm{p}>0.05$; fig. 3a-d and data not shown). The observed histological changes displaying a robust inflammatory response were also not different between CD4-/- or CD8-/- mice and wild-type mice (fig. 3e). These results suggested that adaptive immune responses are not crucial for the development of HP, at least that due to M. avium exposure (i.e. hot tub lung disease).

\section{Relatively short time course of M. avium exposure to develop HP-like reactions}

We next designed an experiment to determine the participation of innate immunity in the pathogenesis of hot tub lung disease. The results confirmed that administration of killed M. avium on only two consecutive days (fig. 4a) elicited similar inflammatory responses to those observed in the 3-week protocol described above (fig. 4). As in the 3-week protocol, killed $M$. avium HP strain instilled in this 1-week protocol caused HP-like reactions that were characterised by neutrophilia and lymphocytosis in the BAL fluid and the lung tissues, as well as elevated levels of IL-12p40, TNF- $\alpha$ and IFN- $\gamma$, but not IL-4, in the BAL fluid (compared with M. avium non-HP strain; total cells, $\mathrm{p}<0.01$; neutrophils, $\mathrm{p}<0.005$; lymphocytes, $\mathrm{p}<0.05$; macrophages, $p>0.05$; eosinophils, $p>0.05$; IL-12p40, $p<0.005$; TNF- $\alpha, \quad p<0.005 ; \quad$ IFN- $\gamma, \quad p<0.05 ;$ IL-4, $p>0.05 ;$ fig. $4 b-f$ and data not shown).

\section{M. avium-induced HP reactions dependent on MyD88}

Using the 1-week protocol, we analysed the signalling pathways of TLRs, which are the best characterised pattern recognition receptors for innate immunity and found that $M$. avium-induced HP-like reactions are dependent on MyD88 (fig. 5). MyD88 and TRIF are two major adaptor molecules for TLR signalling pathways that can be largely classified as either MyD88mediated pathways to induce mainly inflammatory cytokines, such as IL-12 and TNF- $\alpha$, or TRIF-mediated pathways to induce mainly type-I IFN, such as IFN- $\alpha / \beta$ (fig. $5 \mathrm{a}$ ). Therefore, we evaluated whether MyD88- and/or TRIF-mediated pathways are responsible for HP-like reactions after exposure to killed $M$. avium. In comparison with wild-type mice, TRIF-/- mice showed similar responses to killed $M$. avium $\mathrm{HP}$ strain, as indicated by comparable levels of increased total cellularity with neutrophilia and lymphocytosis and elevated Th1-skewing 
a)

Killed M. avium (HP or Non-HP strain) i.n.

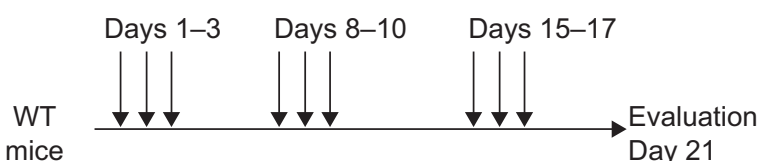
Day 21

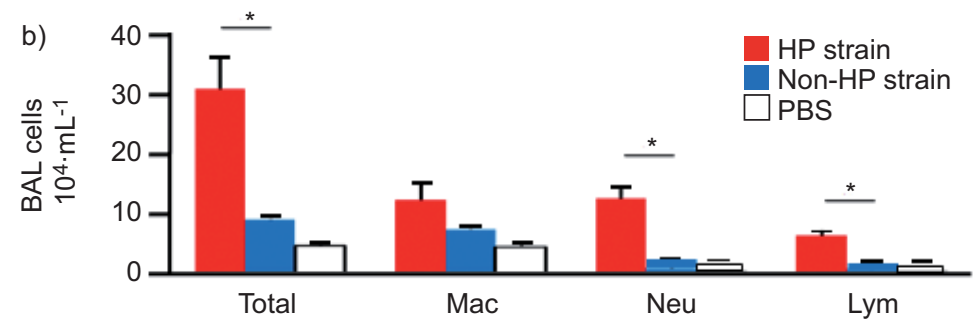

c) $\mathrm{IL}-12 \mathrm{mg} \cdot \mathrm{mL}^{-1}$

d)

$\mathrm{TNF}-\alpha \mathrm{pg} \cdot \mathrm{mL}^{-1}$

e)

IL-4 pg $\cdot \mathrm{mL}^{-1}$
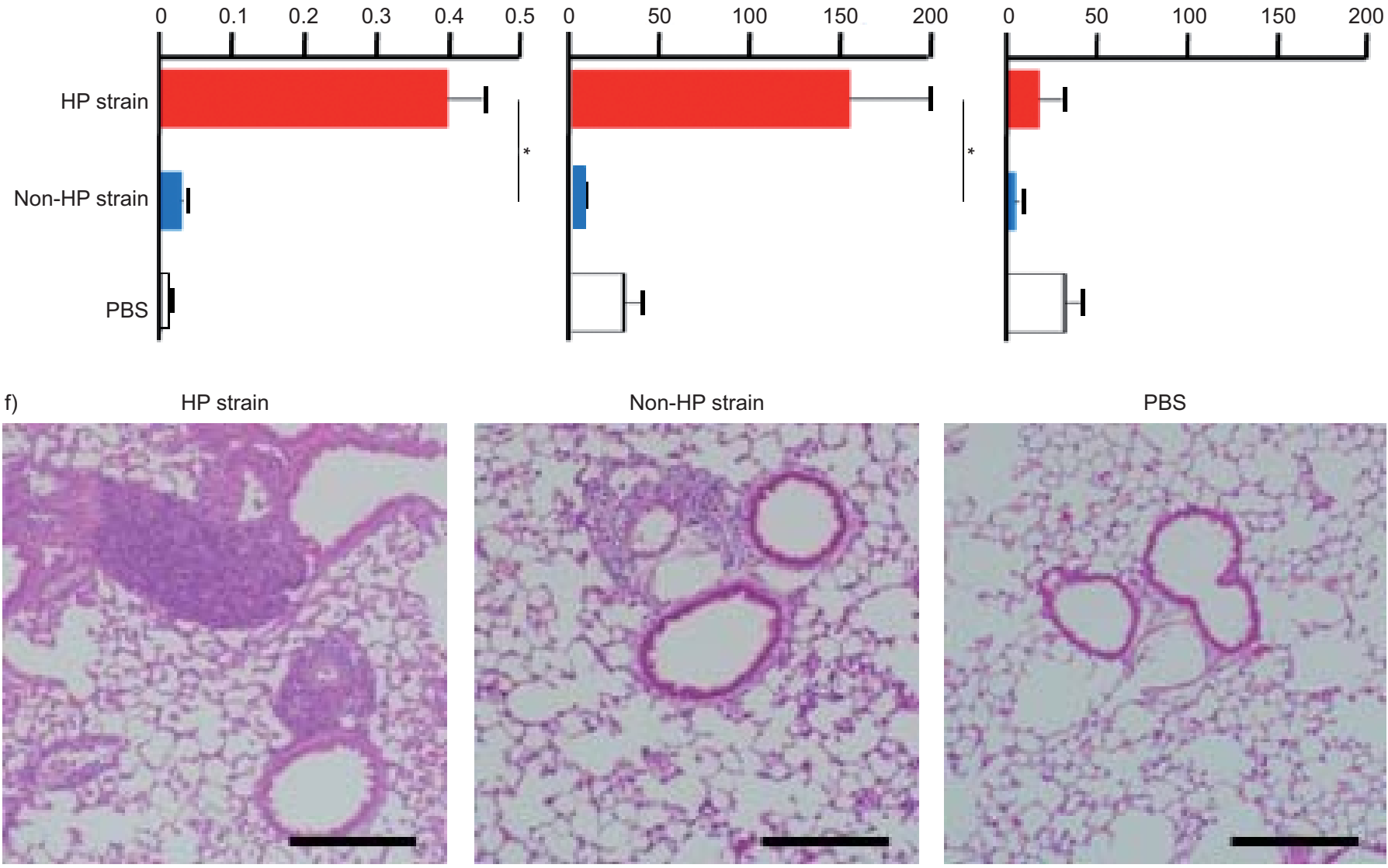

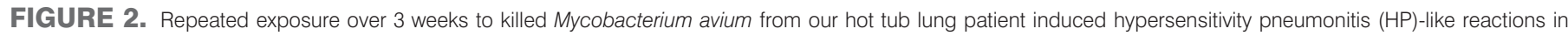

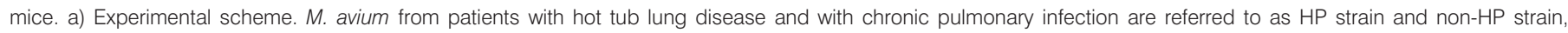

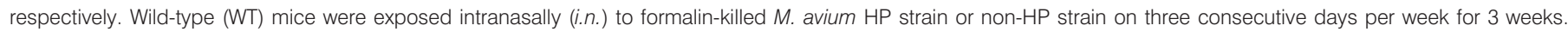

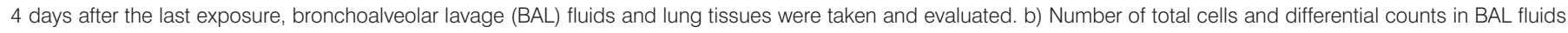

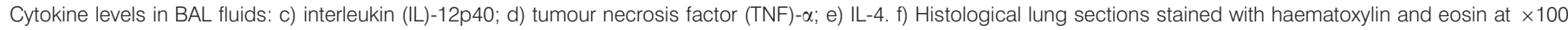

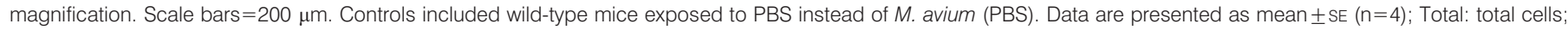
Mac: macrophages; Neu: neutrophils; Lym: Iymphocytes. *: $p<0.05$ for HP strain compared with non-HP strain.

cytokines in the BAL fluid, and cellular infiltration in the lung histology (total cells, $\mathrm{p}>0.05$; neutrophils, $\mathrm{p}>0.05$; lymphocytes, $\mathrm{p}>0.05$; IL-12p40, $\mathrm{p}<0.05$ (but TRIF-/- was higher than wildtype); TNF- $\alpha, \mathrm{p}>0.05 ;$ IFN- $\gamma, \mathrm{p}>0.05 ;$ IL-4, $\mathrm{p}>0.05$; fig. $5 \mathrm{~b}-\mathrm{f}$ and data not shown). In contrast, MyD88-/- mice were significantly resistant to exposure to killed $M$. avium in all inflammatory parameters except IFN- $\gamma$ in the BAL fluid (compared with wildtype mice; total cells, $\mathrm{p}<0.005$; neutrophils, $\mathrm{p}<0.05$; lymphocytes, $\mathrm{p}<0.005 ;$ IL-12p40, $\mathrm{p}<0.05 ;$ TNF- $\alpha, \mathrm{p}<0.05 ;$ IFN- $\gamma$, $\mathrm{p}>0.05$; IL-4, $\mathrm{p}<0.005$ (but MyD88-/- was higher than wildtype); fig. 5b-f and data not shown). These data indicated that M. avium-induced HP-like reactions depend solely on MyD88mediated signalling pathways.

\section{TLR9 leading to MyD88-mediated signalling pathways is critical for promoting $\mathrm{M}$. avium-induced HP reactions}

In the MyD88-mediated signalling pathways, we further investigated and identified TLR9 as the master receptor that leads to $M$. avium-induced HP reactions in a MyD88dependent manner (fig. 6). Therefore, we evaluated the effects of TLR2, TLR4, TLR7 and TLR9 deficiency on the development of M. avium-induced HP reactions, as MyD88 is used universally by all TLRs except TLR3, and TLR1 and TLR6 generally form heterodimers with TLR2 to function [23-25, 27]. Among mutant mice defective in the relevant gene, only TLR9-/- mice failed to mount HP-like reactions after pulmonary exposure to killed $M$. avium HP strain in comparison with 


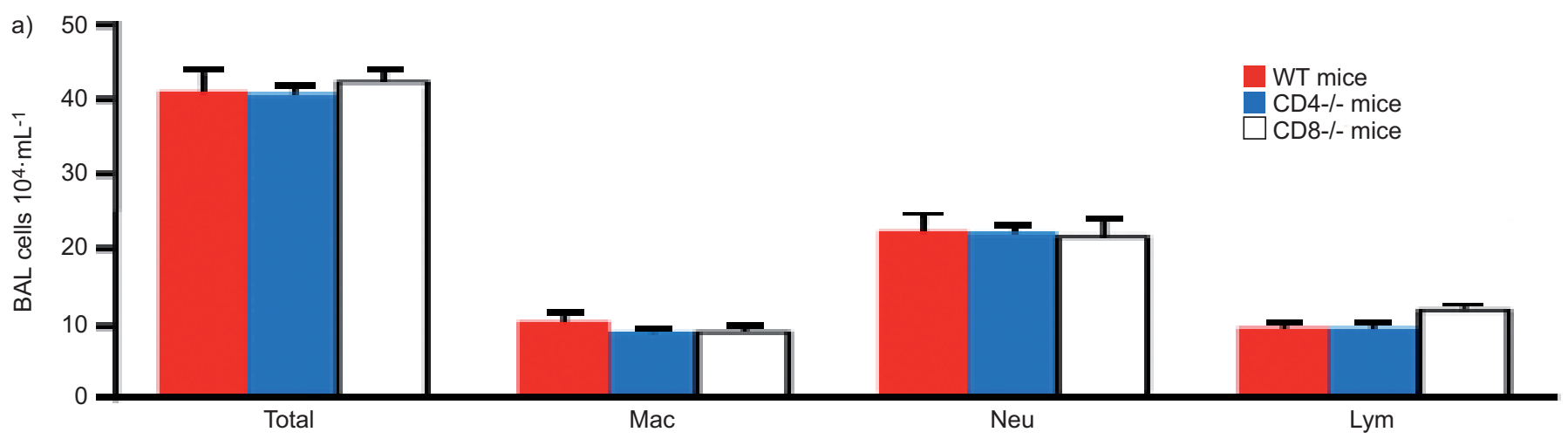

b) $\mathrm{IL}-12 \mathrm{mg} \cdot \mathrm{mL}^{-1}$

c)

TNF- $\alpha p g \cdot \mathrm{mL}^{-1}$

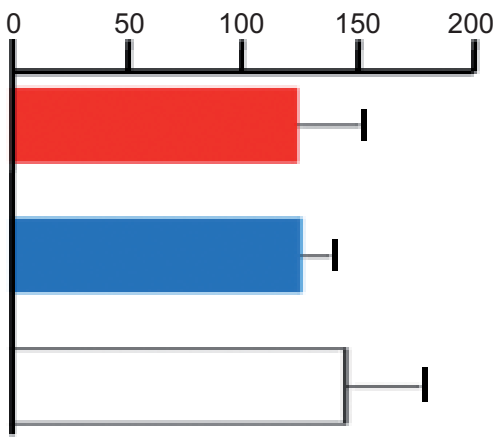

d) $\mathrm{IL}-4 \mathrm{pg} \cdot \mathrm{mL}^{-1}$
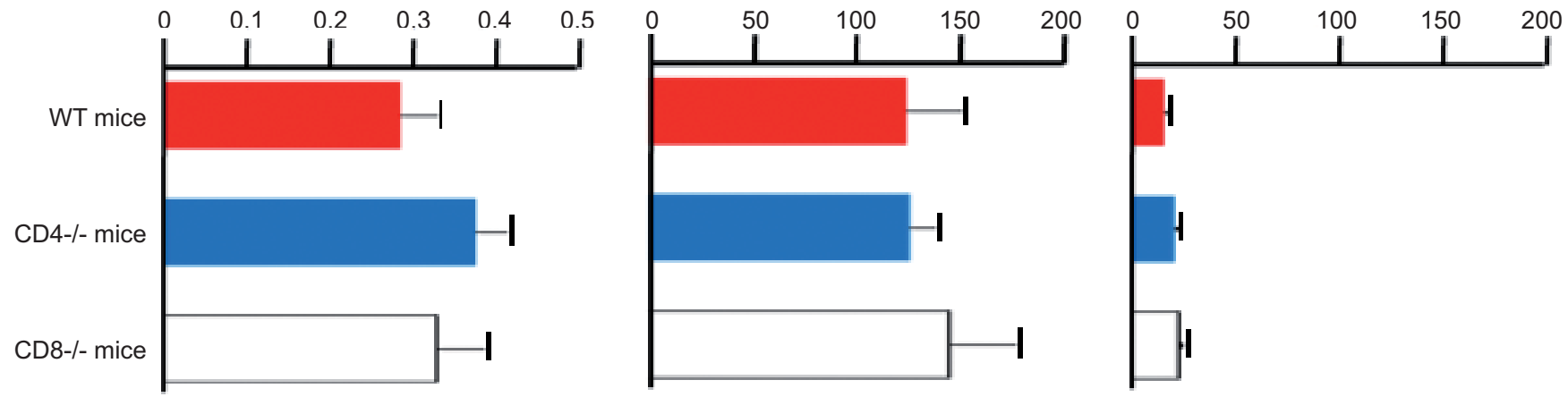

e)

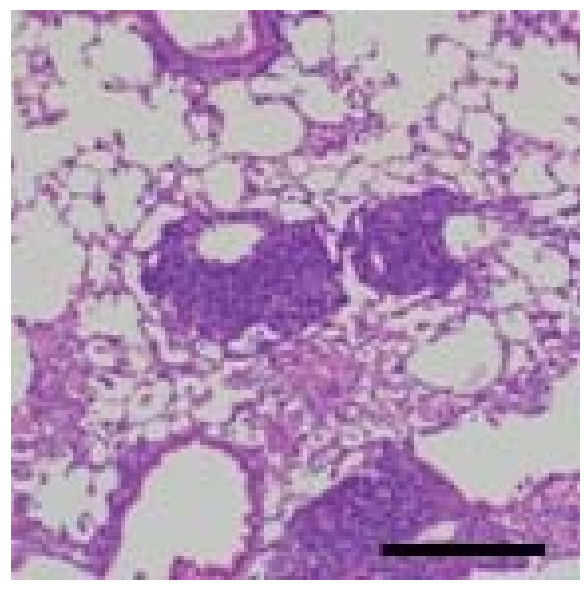

CD4-/- mice

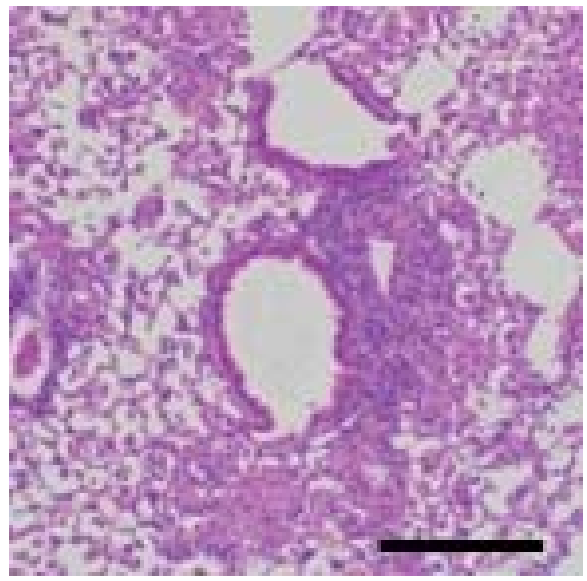

CD8-/- mice

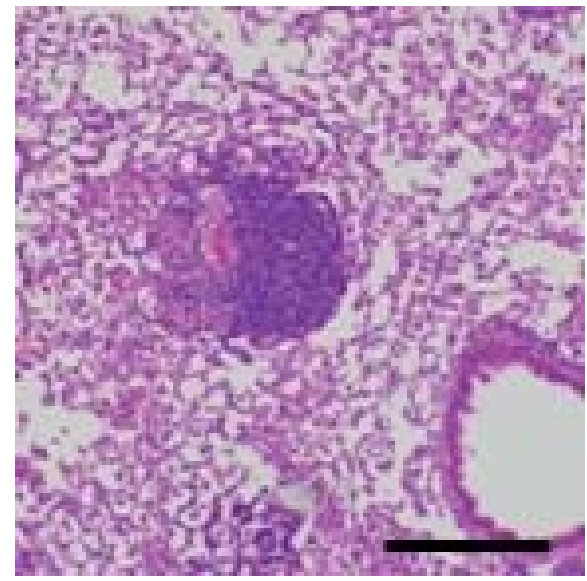

FIGURE 3. Mycobacterium avium-induced HP reactions were unaffected in CD4- or CD8-deficient mice. Wild-type (WT), CD4-/-, and CD8-/- mice were exposed to killed M. avium hypersensitivity pneumonitis strain, as described in fig. 2a. a) Number of total cells and differential counts in BAL fluids. Cytokine levels in BAL fluids: b) interleukin (IL)-12p40; c) tumour necrosis factor (TNF)- $\alpha$; d) IL-4. e) Histological lung sections stained with haematoxylin and eosin at $\times 100$ magnification. Scale bars $=200 \mu \mathrm{m}$. Data are presented as mean $\pm S E(n=5)$. Total: total cells; Mac: macrophages; Neu: neutrophils; Lym: lymphocytes.

wild-type controls; the numbers of BAL total cells, neutrophils, and lymphocytes were significantly decreased in TLR9-/- mice in association with a reduction in the level of Th1-skewing cytokines in the BAL fluid and reductions in peribronchial, perivascular and parenchymal infiltration of inflammatory cells in the lung tissue (total cells, $\mathrm{p}<0.005$; neutrophils, $\mathrm{p}<0.05 ;$ lymphocytes, $\mathrm{p}<0.001 ;$ IL-12p40, $\mathrm{p}<0.01 ; \mathrm{TNF}-\alpha, \mathrm{p}<0.005 ;$ IL-4, $\mathrm{p}>0.05 ;$ fig. 6 ). However, these $M$. avium-induced inflammatory changes were all unaffected by TLR2, TLR4 and TLR7 deficiency when compared with wild-type controls (total cells, $\mathrm{p}>0.05$; neutrophils, $\mathrm{p}>0.05$; lymphocytes, $\mathrm{p}>0.05$; IL-12p40, $\mathrm{p}>0.05$ for TLR4-/- and TLR7-/-, $\mathrm{p}<0.05$ for TLR2 (TLR2 was higher than wild-type); TNF- $\alpha, \mathrm{p}>0.05 ;$ IL-4, $\mathrm{p}>0.05$; fig. 6). Notably, histological analysis of lung tissues revealed that the inflammatory cell infiltrate was slightly increased in TLR2- and TLR4-deficient mice compared with wild-type mice (fig. 6e). These studies indicated that TLR9 is necessary for M. avium-induced HP reactions through MyD88-mediated signalling pathways. 
a)

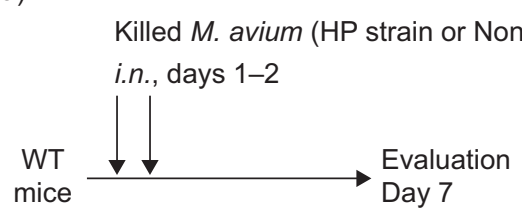

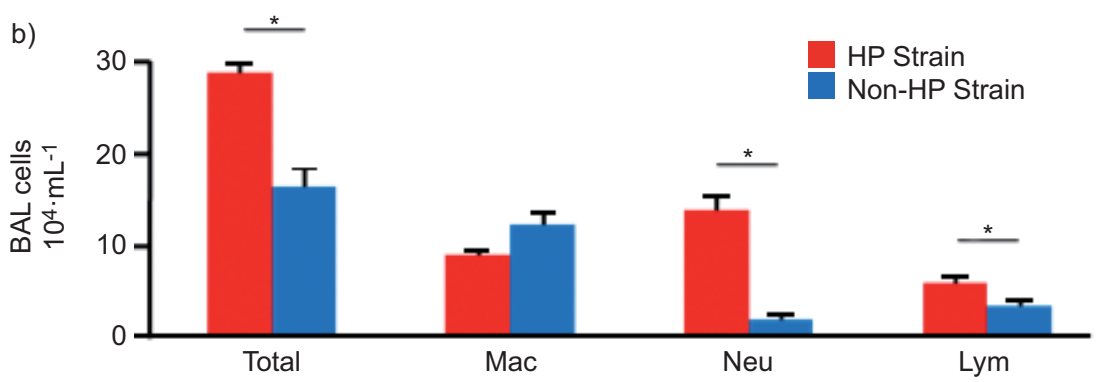

d)

e)

$\quad \mathrm{IL}-4 \mathrm{pg} \cdot \mathrm{mL}^{-1}$
$\mathrm{IL}-12 \mathrm{mg} \cdot \mathrm{mL}^{-1}$

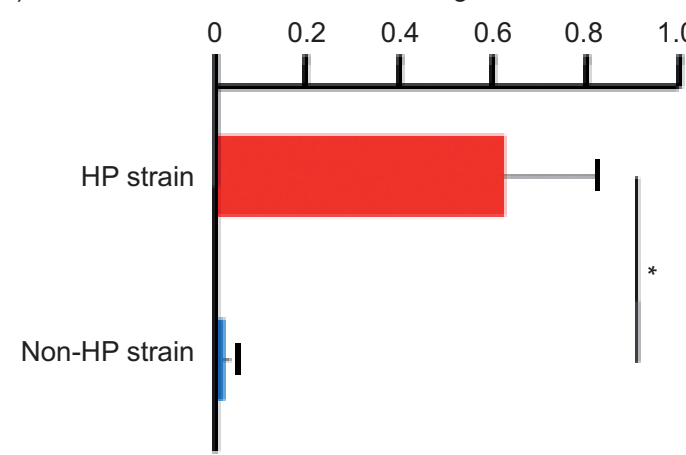

d)

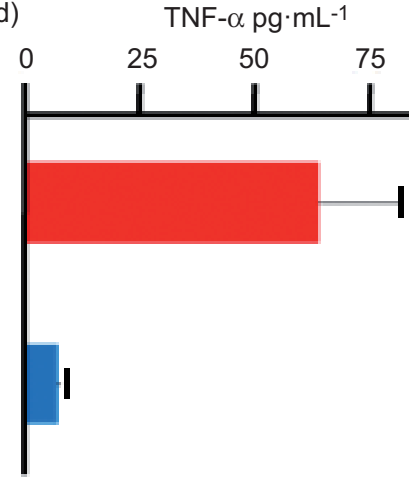

f)

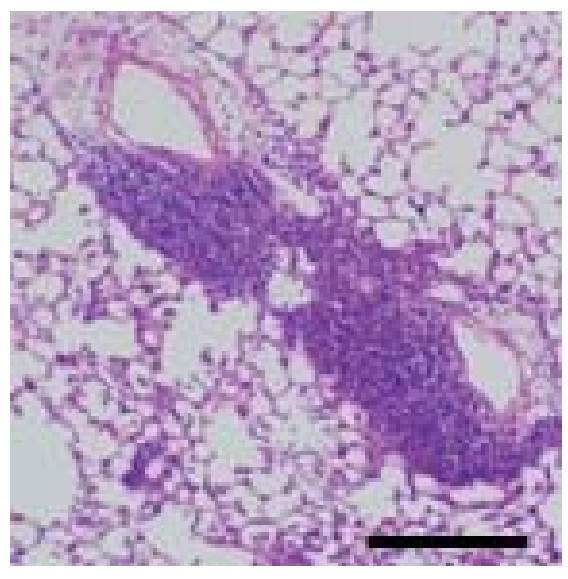

Non-HP strain

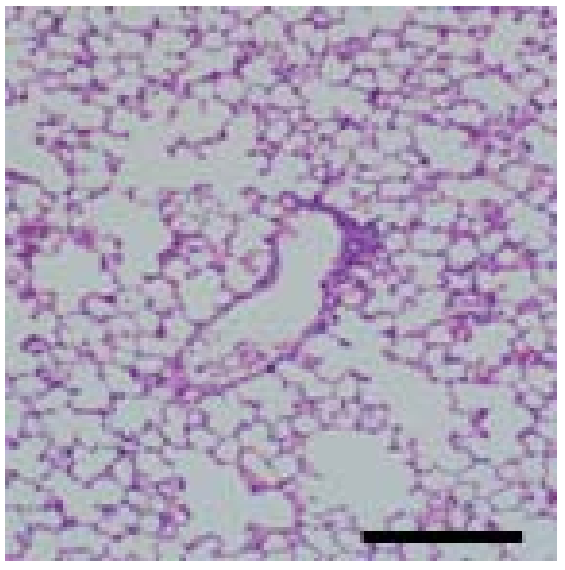

FIGURE 4. Decreased exposure to killed Mycobacterium avium for 1 week also induced hypersensitivity pneumonitis (HP) reactions as in the 3-week exposure protocol. a) Experimental scheme. Wild-type (WT) mice were exposed to formalin-killed $M$. avium HP strain or non-HP strain on two consecutive days. 5 days after the last exposure, bronchoalveolar lavage (BAL) fluids and lung tissues were taken and evaluated. b) Number of total cells and differential counts in BAL fluids. Cytokine levels in BAL fluids: c) interleukin (IL)-12p40; d) tumour necrosis factor (TNF)- $\alpha$; e) IL-4. f) Histological lung sections stained with haematoxylin and eosin at $\times 100$ magnification. Scale bars $=200 \mu \mathrm{m}$. Data are presented as mean \pm SE $(n=4) ;{ }^{*}: p<0.05$ for HP strain compared with non-HP strain. i.n.; intranasally; Total: total cells; Mac: macrophages; Neu: neutrophils; Lym: lymphocytes.

\section{TLR9 engagement in lung CD11C+ cells is responsible for M. avium-induced HP-like reactions}

We also addressed the lung cell type involved in TLR9-MyD88 signalling to generate $M$. avium-induced HP-like reactions. The results supported an essential role of lung CD11c+ cells in the TLR9-mediated inflammatory process (fig. 7). In preliminary in vitro experiments using lung cells isolated from naïve wild-type mice, lung CD11c+ cells secreted much larger amounts of IL-12p40 than did lung CD11c- cells when cultured with killed M. avium HP strain ( $p<0.001$; fig. 7a). This was similar to the increased IL-12p40 secretion observed upon stimulation with synthetic $\mathrm{CpG}$ oligodeoxynucleotides that can be sensed by TLR9; in addition, defective TLR9 in lung CD11c+ cells significantly compromised IL-12p40 secretion in response to killed $M$. avium (wild-type versus TLR9-/CD11c+ cells, $\mathrm{p}<0.005$; fig. 7a). Following the in vitro finding that lung CD11c+ cells, but not lung CD11c- cells, can respond to killed $M$. avium, at least in part, in a TLR9-dependent manner, we examined whether TLR9 deficiency in lung CD11c+ cells could explain the impaired HP-like reactions after M. avium exposure in TLR9-/- mice. For this, we transferred lung CD11c+ or CD11c- cells from wild-type mice intravenously into TLR9-/- recipients and examined the development of allergic inflammation in response to killed M. avium HP strain (fig. 7b). Assessment of lung histology, differential cell counts and cytokine production in BAL fluid demonstrated that lung CD11c+ cells from wild-type mice significantly reconstituted $M$. avium-induced HP-like reactions in TLR9-/- mice subjected to M. avium exposure as compared with lung CD11c- cells (total cells, $\mathrm{p}<0.01$; neutrophils, $\mathrm{p}<0.0005$; lymphocytes, $\mathrm{p}<0.005$; IL-12p40, $\mathrm{p}<0.05$; TNF- $\alpha$, $\mathrm{p}<0.05$; IL-4, $\mathrm{p}>0.05$; fig. 7c-g). Taken together, the results of these in vitro and in vivo studies indicated that in lungs exposed to $M$. avium, lung CD11c+ cells respond to the mycobacterial stimuli through TLR9 engagement and concomitantly facilitate HP-like reactions. 
a) Plasma

membrane

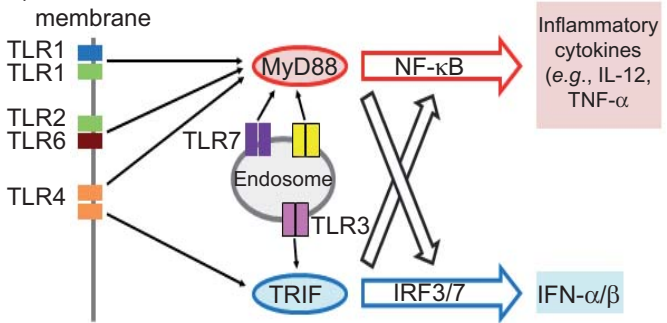

c)

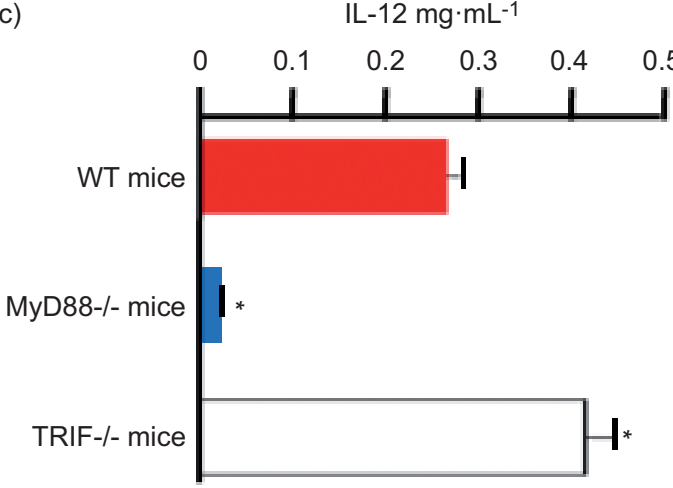

b)

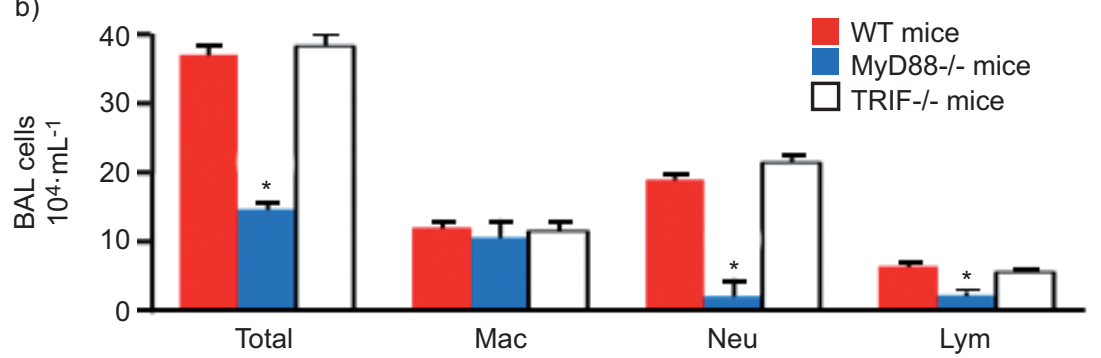

d) e) e) $\quad \mathrm{IL}-4 \mathrm{pg} \cdot \mathrm{mL}^{-1}$ d) $\quad \mathrm{TNF}-\alpha \mathrm{pg} \cdot \mathrm{mL}^{-1}$

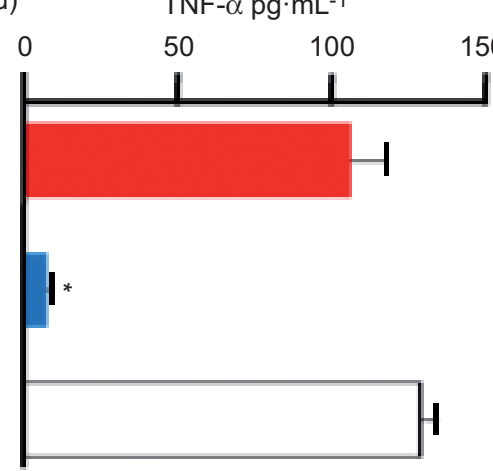

f)

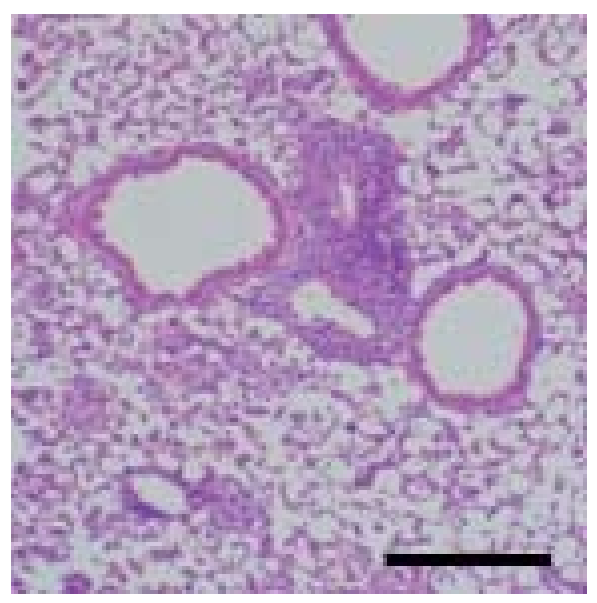

MyD88-/- mice

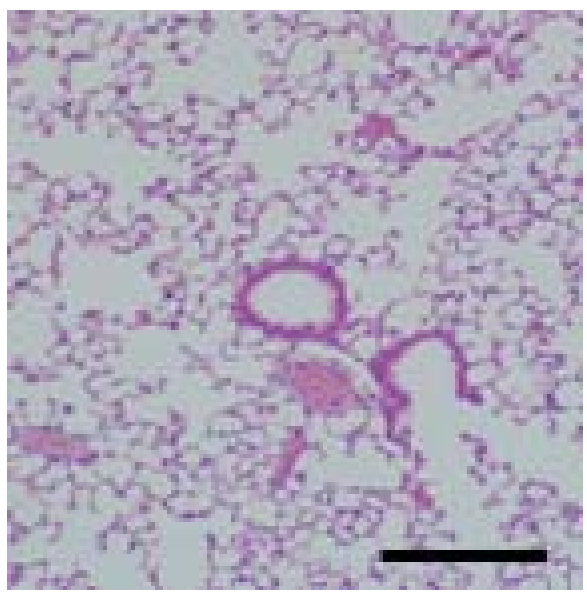

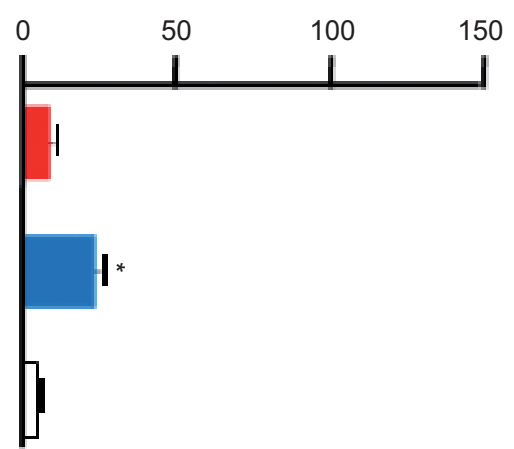

150

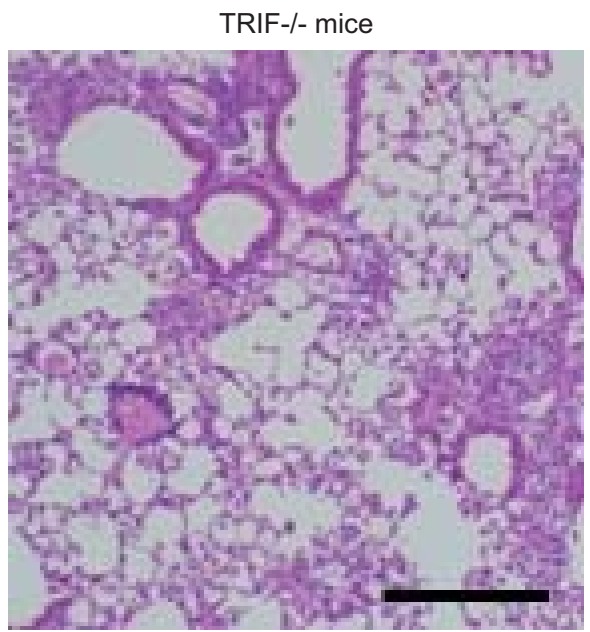

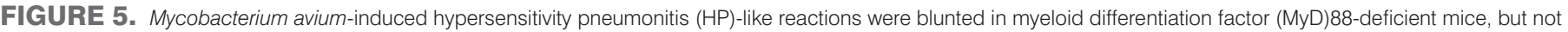

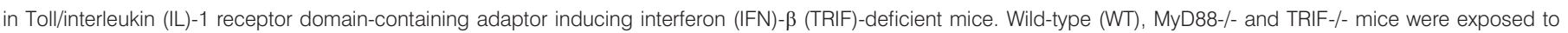

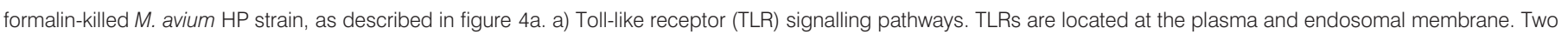

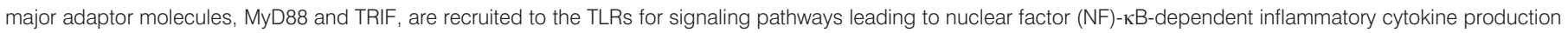

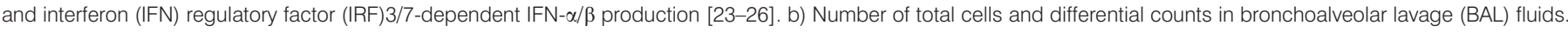
Cytokine levels in BAL fluids: c) IL-12p40; d) tumour necrosis factor (TNF)- $\alpha$; e) IL-4. f) Histological lung sections stained with haematoxylin and eosin at $\times 100$ magnification.

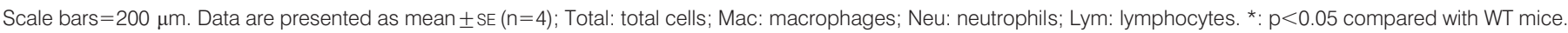

\section{TLR9-mediated increase in number of lung CD11b+ DC subset after pulmonary exposure to killed $\mathrm{M}$. avium HP strain}

The contribution of TLR9 in lung CD11c+ cells to the pathogenesis of $M$. avium-induced HP was further confirmed by our results indicating that pulmonary exposure to killed $M$. avium $\mathrm{HP}$ strain increased the number of the $\mathrm{CD} 11 \mathrm{~b}+$ subset in lung $\mathrm{CD} 11 \mathrm{c}+$ cells (i.e. CD11b+ DCs) via a TLR9-dependent pathway, despite a lack of increase in other subsets of lung CD11c+ cells, including alveolar macrophages (CD11b- CD103-), lung CD103+ DCs (CD11b- CD103+) and plasmacytoid DCs (fig. 8). As determined by flow cytometric analysis of lung CD11c+ cells, the frequency of cells expressing CD11b was increased by pulmonary exposure to killed $M$. avium $\mathrm{HP}$ strain, and this increase was reduced by genetic ablation of TLR9 in HP strain-exposed mice or exposure to non-HP strain (PBS, wildtype, $15 \%$; HP strain, wild-type, 57\%; HP strain, TLR9-/-, 14\%; non-HP strain, wild-type, 38\%; fig. 8a). Unlike the increase in lung CD11b+ DCs, there were no differences in the frequency of lung CD11c+ cells expressing CD103 (i.e. CD103+ DCs) among these groups $(2-4 \%$, fig. $8 \mathrm{a})$. In accordance with the cell frequency, lungs from wild-type mice exposed to M. avium HP 

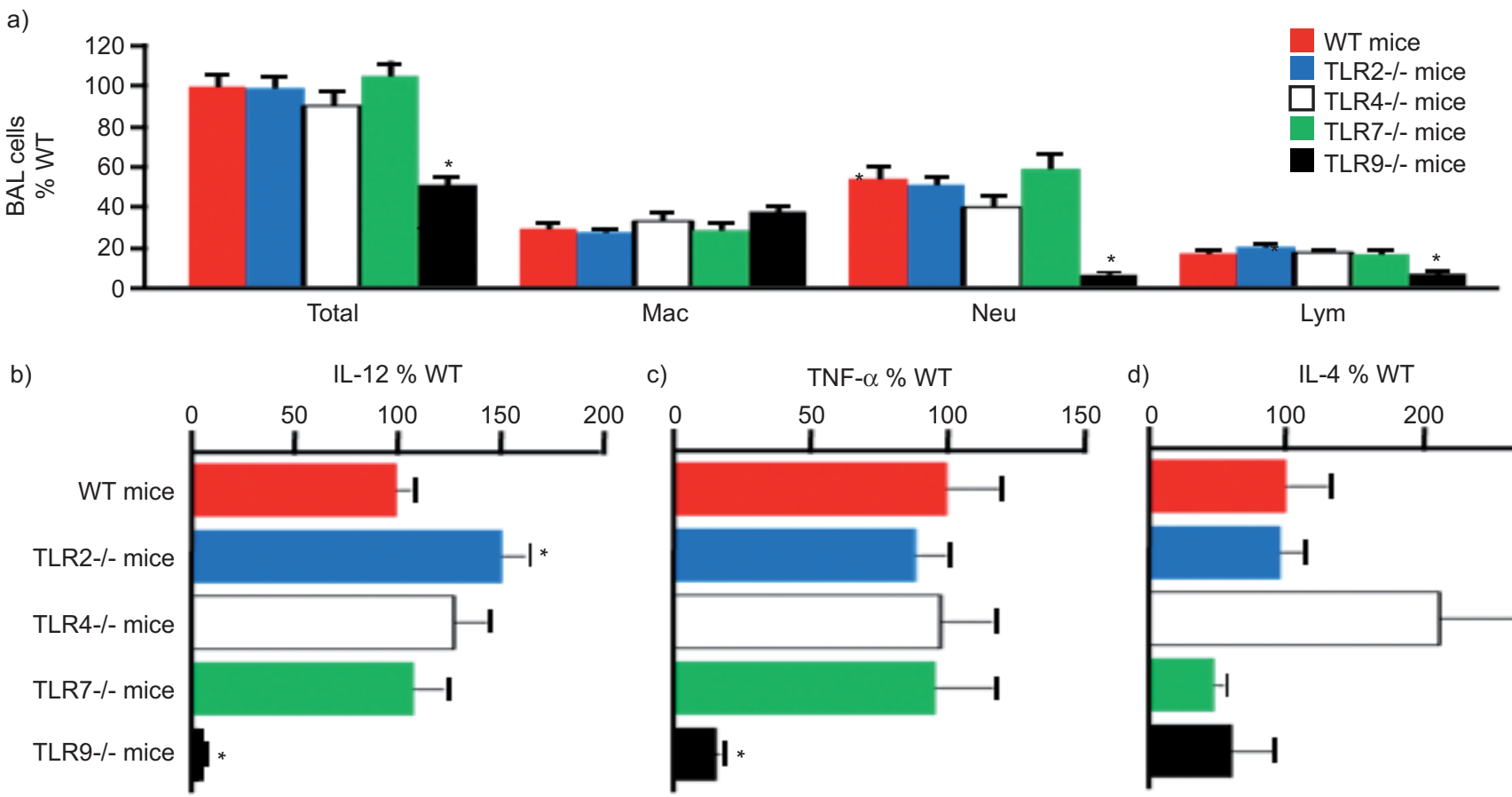

b)

c)

TNF- $\alpha \%$ WT

d)

IL-4 \% WT
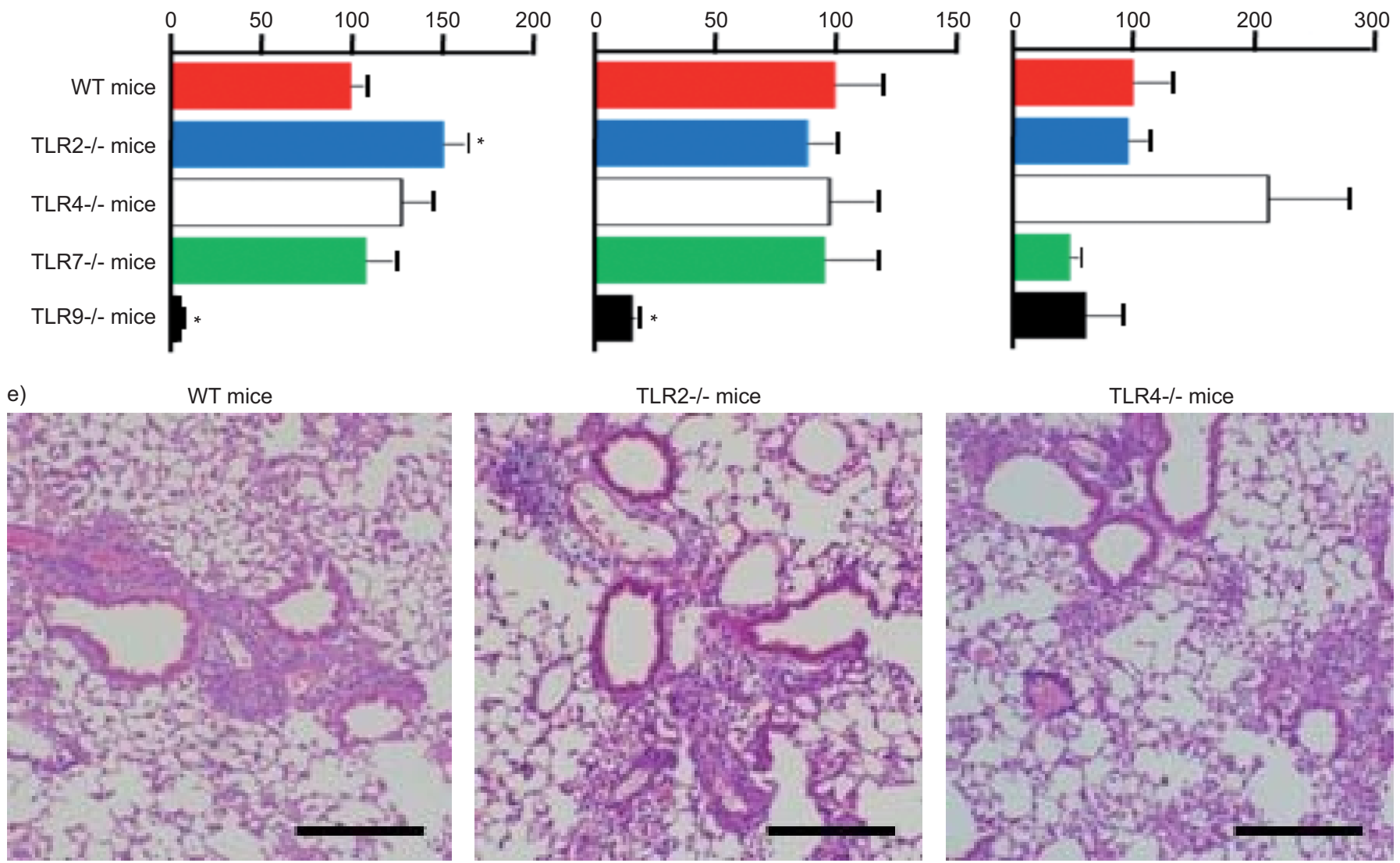

FIGURE 6. Mycobacterium avium-induced hypersensitivity pneumonitis (HP) reactions were attenuated in Toll-like receptor (TLR)9-deficient mice, but not in mice lacking other myeloid differentiation factor (MyD)88-dependent TLRs. Wild-type (WT), TLR2-/-, TLR4-/-, TLR7-/- and TLR9-/- mice were exposed to formalin-killed M. avium HP strain, as described in figure 4a. a) Number of total cells and differential counts in bronchoalveolar lavage (BAL) fluids. Cytokine levels in BAL fluids: b) interleukin (IL)-12p40; c) tumour necrosis factor (TNF)- $\alpha$; d) IL-4. e) Histological lung sections stained with haematoxylin and eosin at $\times 100$ magnification. Scale bars $=200 \mu \mathrm{m}$. Data are presented as mean \pm SE $(n=5)$. Total: total cells; Mac: macrophages; Neu: neutrophils; Lym: lymphocytes. *: $p<0.05$ compared with WT mice.
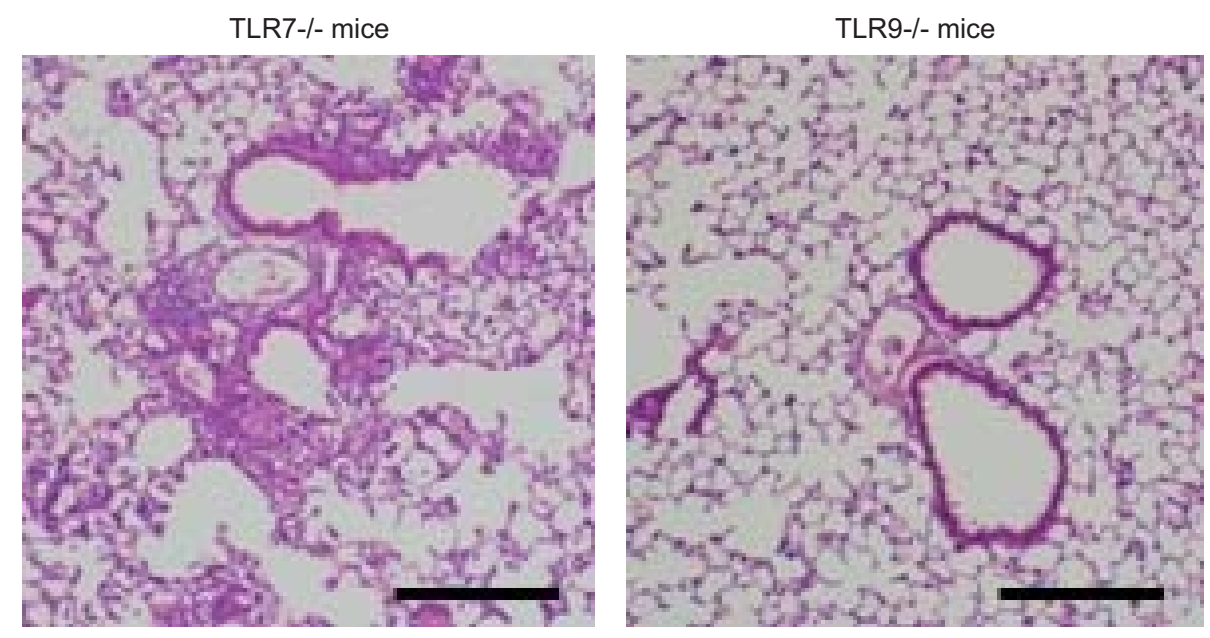
a)

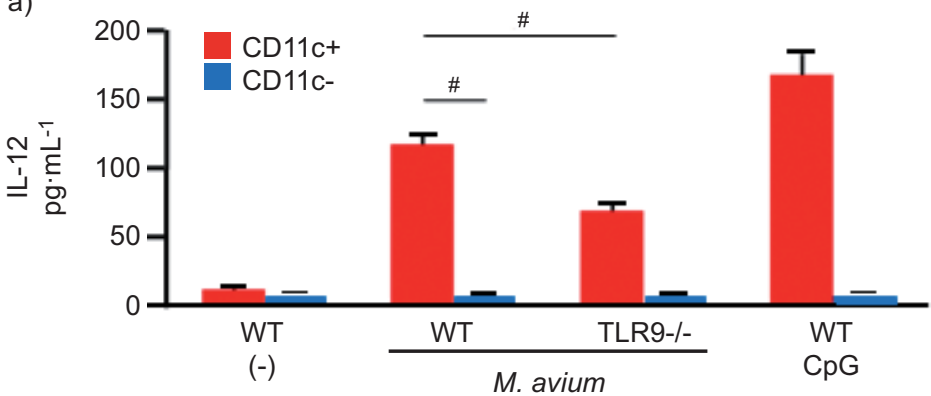

b)

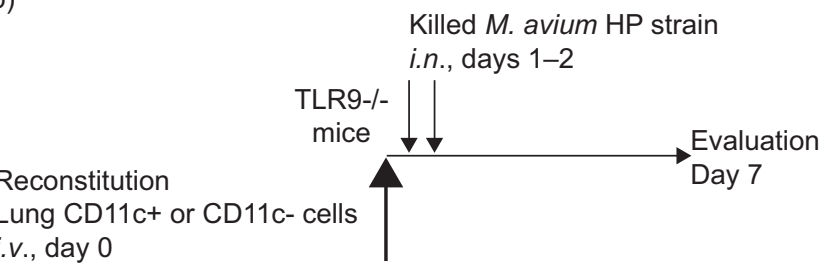

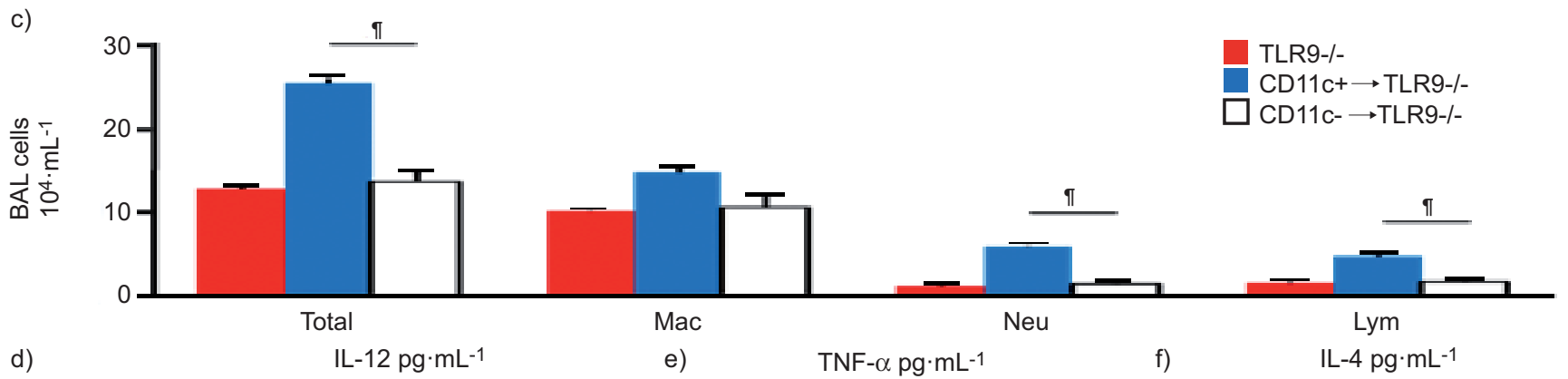

d)

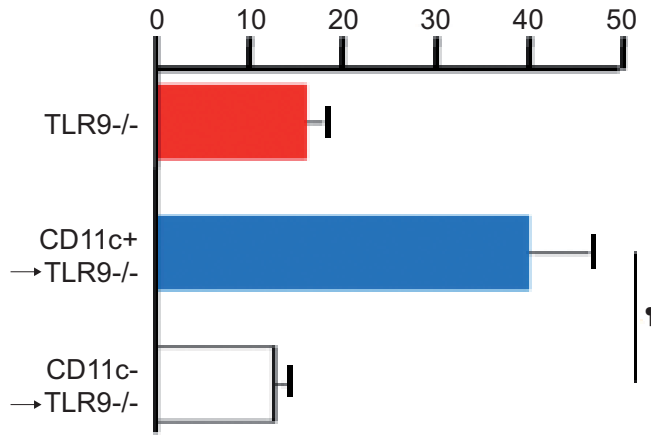

TLR9-/-

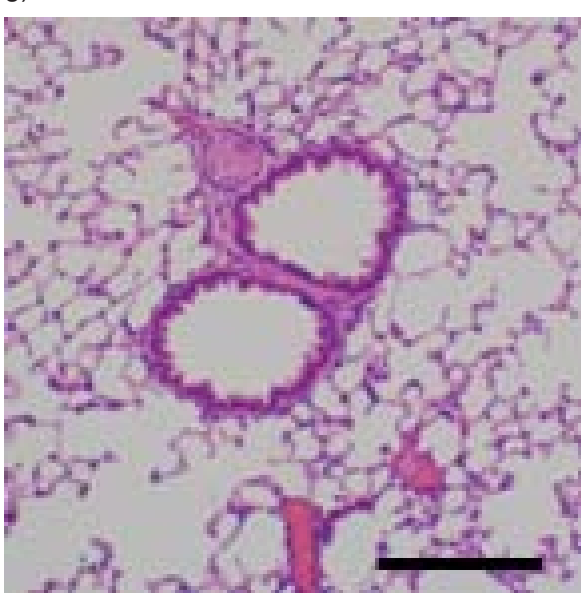

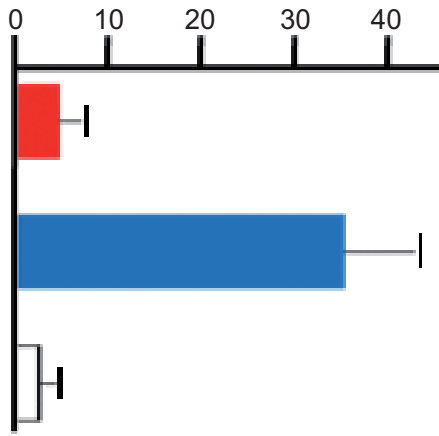

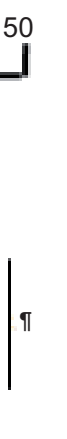

\begin{tabular}{l}
0 \\
\hline 1 \\
1
\end{tabular}

CD11c $\rightarrow$ TLR9-/-

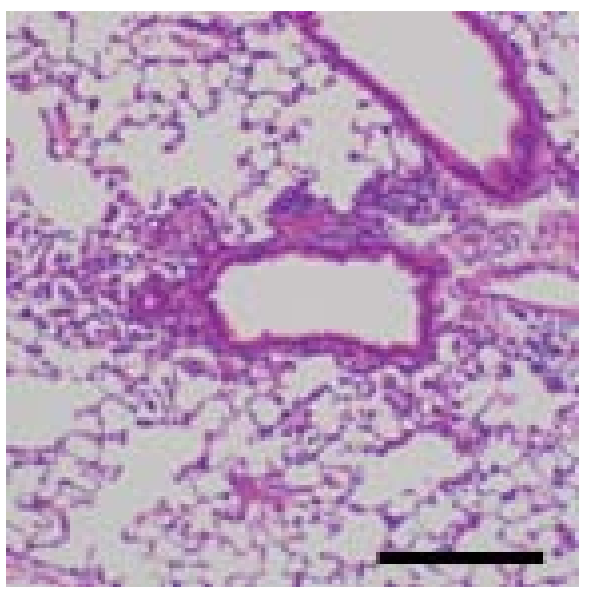

CD11C- $\rightarrow$ TLR9-/-

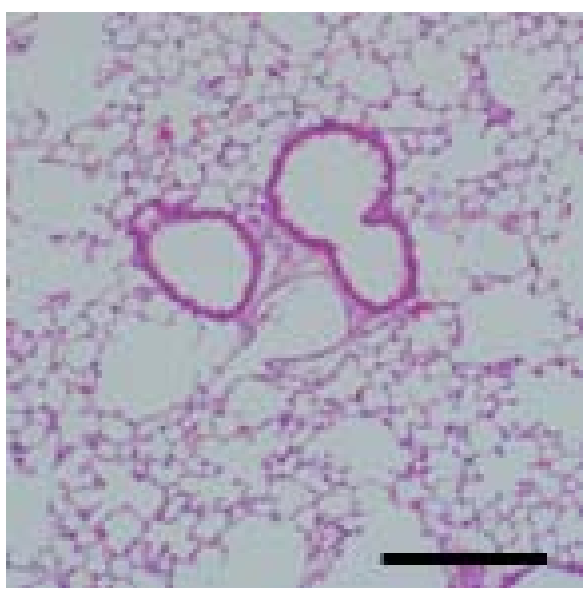

FIGURE 7. Toll-like receptor (TLR)9 in lung CD11c+ cells is responsible for the Mycobacterium avium-induced hypersensitivity pneumonitis (HP) reactions. a) Interleukin (IL)-12p40 secretion from lung CD11c+ or CD11c- cells in response to killed M. avium. CD11C+ and CD11c- cells obtained from lungs of wild-type (WT) and TLR9-/- mice were cultured with formalin-killed M. avium HP strain for $24 \mathrm{~h}$. Controls included WT lung cells cultured without $M$. avium (-), and those cultured with synthetic cytidine-phosphateguanosine (CpG) oligodeoxynucleotides, known as the TLR9 ligand. b) Experimental scheme for panels c-g. Similar to figure 6, TLR9-/- mice were exposed to formalin-killed M. avium HP strain on days 1-2. However, 1 day before exposure to M. avium (day 0), the TLR9-/- mice were reconstituted with lung CD11C+ or CD11c- cells from naive WT mice. c) Number of total cells and differential counts in bronchoalveolar lavage (BAL) fluid. $d-f$ ) Cytokine levels in BAL fluid: d) IL-12p40; e) tumour necrosis factor (TNF)- $\alpha$; f) IL-4. g) Histological lung sections stained with haematoxylin and eosin at $\times 100$ magnification. Scale bars $=200 \mu \mathrm{m}$. Data are presented as mean \pm SE $(\mathrm{n}=3) ;$ i.n.: intranasally; Total: total cells; Mac: macrophages; Neu: neutrophils; Lym: Iymphocytes. ${ }^{\#}: p<0.05$ for CD11c+ WT cells compared with CD11c- WT cells and CD11c+ TLR9-/- cells; $\because \mathrm{p}<0.05$ for CD11c+ cell transfer compared with CD11c- cell transfer. 
a)

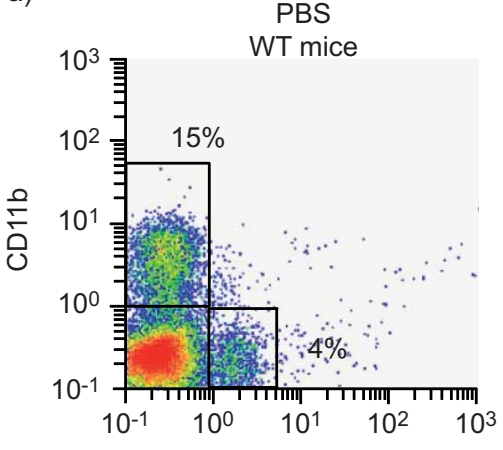

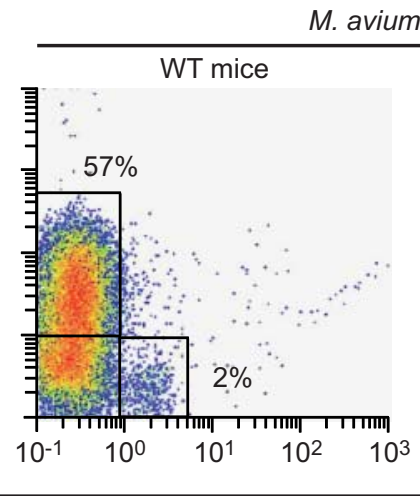

M. avium non-HP strain WT mice

CD103

b)

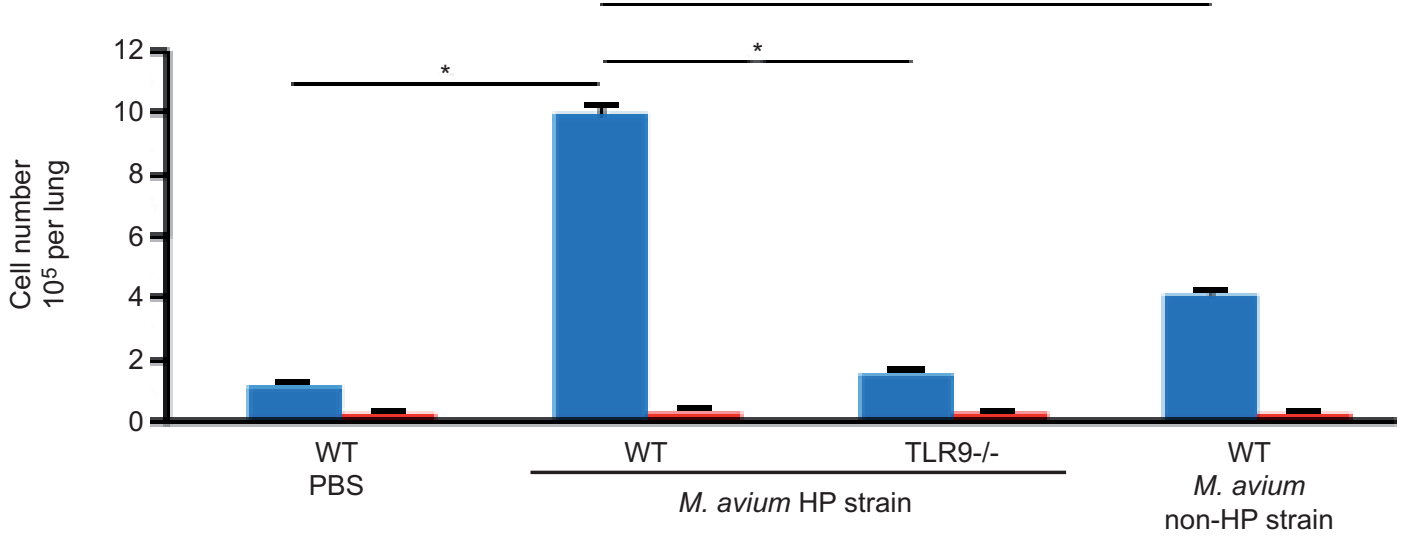

$C D 11 b+D C s$

CD103+ DCs

c)

PBS
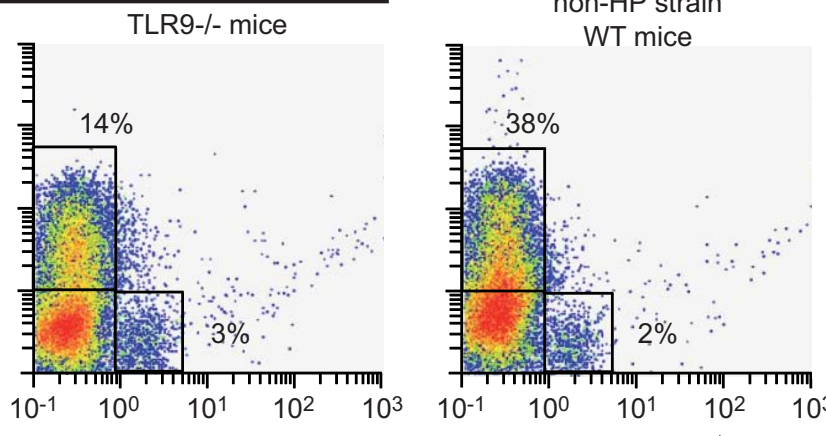

$\begin{array}{lllll}10^{-1} & 10^{0} & 10^{1} & 10^{2} & 10^{3}\end{array}$

non-HP strain

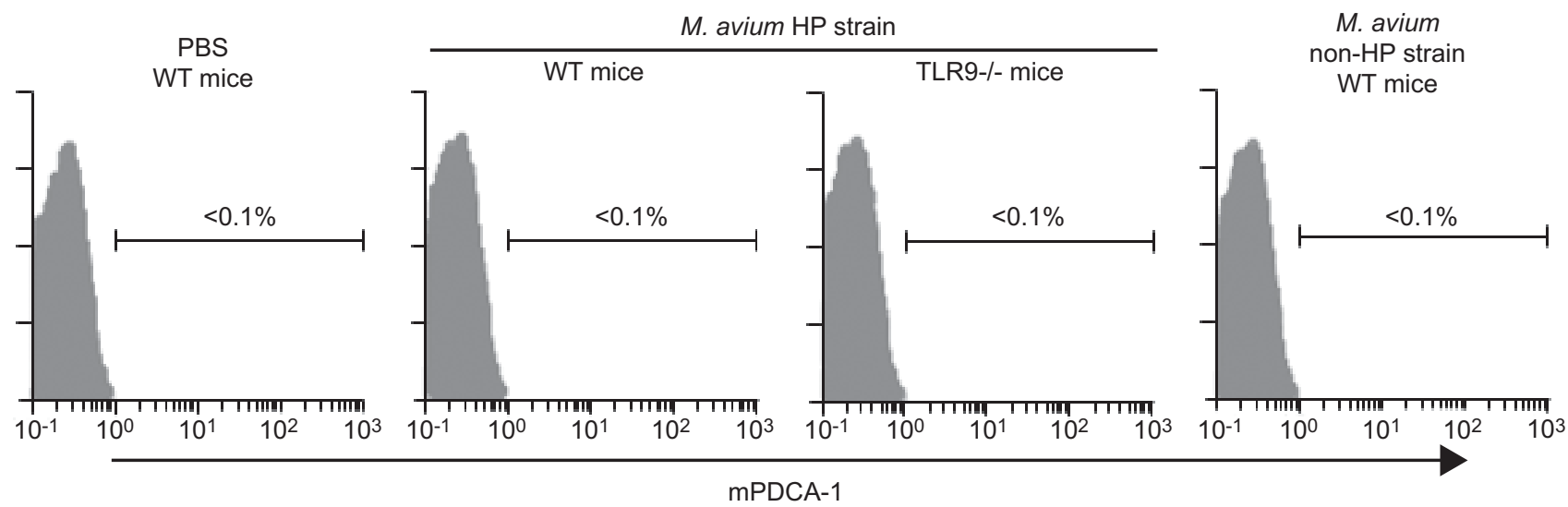

FIGURE 8. Lungs exposed to killed Mycobacterium avium exhibited increased numbers of CD11b+ dendritic cells (DCs), but not plasmacytoid DCs. a, b) Lung CD11b+ and CD103+ DCs. Wild-type (WT) mice and Toll-like receptor (TLR)9-/- mice were exposed to formalin-killed M. avium hypersensitivity pneumonitis (HP) strain, as described in figure 4a. 5 days after the last exposure (day 7), CD11c+ cells were obtained from lungs and stained with antibodies against CD11b and CD103 for 2-colour flow cytometry analysis. a) The percentages of cells in each population, CD11b+CD103- cells (i.e. CD11b+ DCs) and CD11b- CD103+ cells (i.e. CD103+ DCs). b) Absolute numbers of cells per whole lungs of mice. Data are presented as mean \pm SE $(n=3)$. c) Lung plasmacytoid DCs. The experiment was similar to that described in (a) and (b), but all lung cells were stained with anti-mouse plasmacytoid dendritic cell antigen-1 (mPDCA-1) antibody for one-colour flow cytometry analysis. The numbers in histograms denote the percentages of mPDCA-1+ cells (i.e. plasmacytoid DCs). For all panels, controls included WT mice exposed to PBS instead of killed M. avium, and those exposed to M. avium non-HP strain. *: $p<0.05$ compared with WT mice exposed to M. avium HP strain.

strain showed a significant increase in the absolute number of $\mathrm{CD} 11 \mathrm{~b}+\mathrm{DCs}$ in comparison with those from all other control mice (PBS, $\mathrm{p}<0.0005$; TLR9-/-, $\mathrm{p}<0.0005$; non-HP strain, $\mathrm{p}<0.00005$; fig. 8b). However, the absolute numbers of lung
CD103+ DCs were very small and remained unchanged in all groups ( $p>0.05$; fig. $8 b$ ). In addition, the frequencies of lung plasmacytoid DCs positive for mPDCA- 1 were all $<0.1 \%$ and remained unchanged in all groups ( $\mathrm{p}>0.05$; fig. $8 \mathrm{c})$. Thus, lung 
CD11b+ DCs play an important role in the development of mycobacteria-induced HP, i.e. hot tub lung disease, by sensing and transducing the mycobacterial stimuli via the TLR9-MyD88 signalling pathways to induce allergic inflammation.

\section{DISCUSSION}

The results of the present study have clarified the pathogenesis of mycobacteria-induced HP (hot tub lung) in a mouse model using $M$. avium isolated from a patient with this disease. The formalin-killed M. avium strain from the hot tub lung patient, but not M. avium strain from a patient with chronic pulmonary infection, caused severe allergic granulomatous pneumonitis in wild-type mice. Although the allergic inflammation was not altered in mice lacking key molecules involved in adaptive immunity (i.e. CD4 and CD8), mice deficient in MyD88, a crucial TLR signalling adaptor, showed impaired inflammatory response against mycobacterial inhalation. Among the MyD88-mediated signalling pathways, TRL9 signaling in lung CD11b+ DCs was shown to be required for development of hypersensitivity lung inflammation associated with $M$. avium exposure.

Previous reports have outlined numerous types of causative agent for HP [1-3]. A recent report from the Mayo Clinic indicated that $M$. avium-intracellulare complex from hot tub water is the most frequent cause after avian antigens, accounting for approximately $30 \%$ of cases with $\mathrm{HP}$ where the aetiological agent was identified [4]. However, it has not been clarified whether the clinicopathology of hot tub lung disease involves an infectious process, a hypersensitivity reaction, or both $[9,12]$. In addition, given clinical observations indicating the lack of serum immunoglobulin precipitins to mycobacterial antigens in this disease, some have assumed that another agent contaminating hot water aerosols is causal in the hypersensitivity response, whereas others have argued that it is a direct mycobacterial infection rather than a hypersensitivity phenomenon $[7,28]$. To address the underlying pathophysiology of hot tub lung disease, the present study demonstrated that HP-like reactions take place in mice subjected solely to formalin-killed $M$. avium from a patient without any immunogenic cofactors, such as adjuvant, and that mycobacterial inflammation emerges even in genetically engineered mice with compromised ability to generate specific antibody responses. The data clearly indicated that the immunostimulatory capacity of the mycobacteria enables the exposed host to develop $\mathrm{HP}$ as an innate immune response, and that the pathology is related neither to mycobacterial infectious capacity nor to antigen-specific humoral immune response of the exposed host.

To gain insight into the pathological mechanism of HP, several animal models have been investigated, the most common of which is the mouse model of farmer's lung, where HP is clinically caused by inhalation of thermophilic actinomycetes (e.g. Saccharopolyspora rectivirgula) proliferating in damp hay [29-31]. Using the mouse S. rectivirgula-induced farmer's lung model, the role of Th1 CD4+ lymphocytes and the involvement of cellular and humoral adaptive immunity have been studied and moderately well documented [32-38]. Nevertheless, in a newly established mouse model of hot tub lung, we found that pulmonary hypersensitivity reactions against inhaled $M$. avium emerge even in genetically engineered mice deficient in CD4+ Tcells and CD8+ T-cells, which play an indispensable role in adaptive immune responses. These findings prompted us to further investigate the pathological role of innate immune response mediated by pattern recognition receptors (PRRs), focusing on TLRs as the most extensively studied PRRs [27, 39, 40]. Our results indicated that TLR9-MyD88 signalling in lung $\mathrm{CD} 11 \mathrm{~b}+\mathrm{DCs}$ contributes to the pathogenesis of $\mathrm{HP}$ that is ascribed to inhaled $M$. avium. These data were supported by previous studies, in which lung CD11c+ cells, MyD88 and MyD88-mediated protein kinase D1 were shown to be associated with the neutrophilic inflammatory response in a mouse farmer's lung model with $S$. rectivirgula exposure [41-43]. Thus, the results of the present and previous studies demonstrated that genetic deficiency of TLR2 represents no impact on HP-like reactions to $M$. avium and S. rectivirgula [43]. Despite these observations, FONG et al. [44] reported that the incidence of $S$. rectivirgula-induced farmer's lung in mouse depends on TLR6, which is considered to function only as a heterodimer with TLR2. An as-yet undetermined signalling pathway may explain the relevance of TLR2/TLR6 signalling for induction of HP.

DCs are widely distributed cells that are specialised for induction of immune responses and tissue-associated DC subsets have been described in some organs [45, 46]. The lung has been reported to contain three major DC subsets, the $\mathrm{CD} 11 \mathrm{~b}+, \mathrm{CD} 103+$ and plasmacytoid DC populations [20]. In this context, the present study demonstrates that pulmonary exposure to $M$. avium HP strain increased the number of lung CD11b+ DCs through TLR9 triggering. However, the comparable numbers of CD103+ and plasmacytoid DCs in the lungs between control and $M$. avium exposure suggest a minimal role of these DC subsets, if any, in the pathogenesis of hot tub lung disease. The observations in the present study are consistent with the finding that $\mathrm{CpG}$-containing immunostimulatory DNA sequences brought about TLR9-dependent lung inflammation without plasmacytoid DCs, which are known to produce large quantities of type I IFN upon TLR9 stimulation [47].

HP generally occurs in only $\sim 10 \%$ of subjects exposed to eliciting agents $[48,49]$. The underlying reasons are postulated to be immunogenicity of the agents, intensity and duration of exposure and susceptibility of the host [1-3]. The results of the present study demonstrating that $M$. avium isolated from a patient with hot tub lung disease, but not that from one with chronic pulmonary infection, brought about HP-like inflammatory responses in exposed mice underscore the immunostimulatory potency of inhaled aetiological agents as an important pathogenetic factor of HP. Our finding that the oligodeoxynucleotide-sensing TLR9 contributes to the pathogenesis of hot tub lung disease suggests that a comparative sequence analysis of the M. avium $\mathrm{HP}$ and non-HP strains may reveal some sequence motifs that can potentially enhance immune responses. Although the recovery of M. avium isolates from the patient's sputum and the drain of his bathroom with identical VNTR patterns suggested that the source of the patient's $M$. avium was the bathroom in his home, no other family members using the same bathroom were affected with hot tub lung disease. Taken together, these observations suggest that pulmonary exposure to a highly immunogenic strain of $M$. avium is necessary, but not sufficient, for the pathogenicity of hot tub lung, and host propensity to develop the disease may also be required. Further studies are needed to clarify these mechanisms by characterising the $M$. avium 
strains used in this study in more detail and to identify factors responsible for the pathogenicity of hot tub lung disease.

\section{SUPPORT STATEMENT}

These studies were supported, in part, by the Ministry of Education, Culture, Sports, Science, and Technology (Tokyo, Japan), the Core Research for Evolutional Science and Technology Program of the Japan Science and Technology Agency (Tokyo, Japan), and the Adaptable and Seamless Technology Transfer Program of the Japan Science and Technology Agency (Tokyo, Japan).

\section{STATEMENT OF INTEREST}

None declared.

\section{ACKNOWLEDGEMENTS}

We thank M. Takahashi (Tohoku University, Sendai, Japan) for technical assistance.

\section{REFERENCES}

1 Girard M, Lacasse Y, Cormier Y. Hypersensitivity pneumonitis. Allergy 2009; 64: 322-334.

2 Hirschmann JV, Pipavath SN, Godwin JD. Hypersensitivity pneumonitis: a historical, clinical, and radiologic review. Radiographics 2009; 29: 1921-1938.

3 Madison JM. Hypersensitivity pneumonitis: clinical perspectives. Arch Pathol Lab Med 2008; 132: 195-198.

4 Hanak V, Golbin JM, Ryu JH. Causes and presenting features in 85 consecutive patients with hypersensitivity pneumonitis. Mayo Clin Proc 2007; 82: 812-816.

5 Woda BA. Hypersensitivity pneumonitis: an immunopathology review. Arch Pathol Lab Med 2008; 132: 204-205.

6 Marras TK, Wallace RJ Jr, Koth LL, et al. Hypersensitivity pneumonitis reaction to Mycobacterium avium in household water. Chest 2005; 127: 664-671.

7 Sood A, Sreedhar R, Kulkarni P, et al. Hypersensitivity pneumonitis-like granulomatous lung disease with nontuberculous mycobacteria from exposure to hot water aerosols. Environ Health Perspect 2007; 115: 262-266.

8 Glassroth J. Pulmonary disease due to nontuberculous mycobacteria. Chest 2008; 133: 243-251.

9 Griffith DE, Aksamit T, Brown-Elliott BA, et al. An official ATS/ IDSA statement: diagnosis, treatment, and prevention of nontuberculous mycobacterial diseases. Am J Respir Crit Care Med 2007; 175: 367-416.

10 Martinez S, McAdams HP, Batchu CS. The many faces of pulmonary nontuberculous mycobacterial infection. AJR Am J Roentgenol 2007; 189: 177-186.

11 Piersimoni C, Scarparo C. Pulmonary infections associated with non-tuberculous mycobacteria in immunocompetent patients. Lancet Infect Dis 2008; 8: 323-334.

12 Waller EA, Roy A, Brumble L, et al. The expanding spectrum of Mycobacterium avium complex-associated pulmonary disease. Chest 2006; 130: 1234-1241.

13 Yamamoto M, Sato S, Hemmi H, et al. Role of adaptor TRIF in the MyD88-independent toll-like receptor signaling pathway. Science 2003; 301: 640-643.

14 Kikuchi T, Watanabe A, Gomi K, et al. Association between mycobacterial genotypes and disease progression in Mycobacterium avium pulmonary infection. Thorax 2009; 64: 901-907.

15 Damayanti T, Kikuchi T, Zaini J, et al. Serial OX40 engagement on $\mathrm{CD} 4+\mathrm{T}$ cells and natural killer $\mathrm{T}$ cells causes allergic airway inflammation. Am J Respir Crit Care Med 2010; 181: 688-698.

16 Kikuchi T, Kobayashi T, Gomi K, et al. Dendritic cells pulsed with live and dead Legionella pneumophila elicit distinct immune responses. J Immunol 2004; 172: 1727-1734.
17 Ishii KJ, Kawagoe T, Koyama S, et al. TANK-binding kinase-1 delineates innate and adaptive immune responses to DNA vaccines. Nature 2008; 451: 725-729.

18 Beauchamp NM, Busick RY, Alexander-Miller MA. Functional divergence among CD103+ dendritic cell subpopulations following pulmonary poxvirus infection. J Virol 2010; 84: 10191-10199.

19 del Rio ML, Bernhardt G, Rodriguez-Barbosa JI, et al. Development and functional specialization of CD103+ dendritic cells. Immunol Rev 2010; 234: 268-281.

20 Sung SS, Fu SM, Rose CE Jr, et al. A major lung CD103 $(\alpha \mathrm{E})-\beta 7$ integrin-positive epithelial dendritic cell population expressing Langerin and tight junction proteins. J Immunol 2006; 176: 2161-2172.

21 Zaini J, Andarini S, Tahara M, et al. OX40 ligand expressed by DCs costimulates NKT and CD4+ Th cell antitumor immunity in mice. J Clin Invest 2007; 117: 3330-3338.

22 Hartman TE, Jensen E, Tazelaar HD, et al. CT findings of granulomatous pneumonitis secondary to Mycobacterium aviumintracellulare inhalation: "hot tub lung". AJR Am J Roentgenol 2007; 188: 1050-1053.

23 Kawai T, Akira S. The role of pattern-recognition receptors in innate immunity: update on Toll-like receptors. Nat Immunol 2010; 11: 373-384.

24 Takeuchi O, Akira S. Pattern recognition receptors and inflammation. Cell 2010; 140: 805-820.

25 Tapping RI. Innate immune sensing and activation of cell surface Toll-like receptors. Semin Immunol 2009; 21: 175-184.

26 Opitz B, van Laak V, Eitel J, et al. Innate immune recognition in infectious and noninfectious diseases of the lung. Am J Respir Crit Care Med 2010; 181: 1294-1309.

27 Monie TP, Bryant CE, Gay NJ. Activating immunity: lessons from the TLRs and NLRs. Trends Biochem Sci 2009; 34: 553-561.

28 Mery A, Horan RF. Hot tub-related Mycobacterium avium intracellulare pneumonitis. Allergy Asthma Proc 2002; 23: 271-273.

29 Blyth W, Wardrop VE. Particulate and soluble antigens of Micropolyspora faeni in experimental allergic alveolitis of the mouse. J Med Microbiol 1977; 10: 331-346.

30 Bogaert P, Tournoy KG, Naessens $T$, et al. Where asthma and hypersensitivity pneumonitis meet and differ: noneosinophilic severe asthma. Am J Pathol 2009; 174: 3-13.

31 Schuyler M, Gott K, Haley P. Experimental murine hypersensitivity pneumonitis. Cell Immunol 1991; 136: 303-317.

32 Denis $\mathrm{M}$, Cormier $\mathrm{Y}$, Laviolette $\mathrm{M}$, et al. $\mathrm{T}$ cells in hypersensitivity pneumonitis: effects of in vivo depletion of $\mathrm{T}$ cells in a mouse model. Am J Respir Cell Mol Biol 1992; 6: 183-189.

33 Gudmundsson G, Hunninghake GW. Interferon- $\gamma$ is necessary for the expression of hypersensitivity pneumonitis. J Clin Invest 1997; 99: 2386-2390.

34 Hwang SJ, Kim S, Park WS, et al. IL-4-secreting NKT cells prevent hypersensitivity pneumonitis by suppressing IFN- $\gamma$-producing neutrophils. J Immunol 2006; 177: 5258-5268.

35 Jimenez-Alvarez L, Zuniga J, Gaxiola M, et al. Inflammatory response and dynamics of lung $\mathrm{T}$ cell subsets in Th1, Th2 biased and Th2 deficient mice during the development of hypersensitivity pneumonitis. Exp Mol Pathol 2010; 88: 407-415.

36 Matsuno Y, Ishii Y, Yoh K, et al. Overexpression of GATA-3 protects against the development of hypersensitivity pneumonitis. Am J Respir Crit Care Med 2007; 176: 1015-1025.

37 Schuyler M, Gott K, Cherne A, et al. Th1 CD4+ cells adoptively transfer experimental hypersensitivity pneumonitis. Cell Immunol 1997; 177: 169-175.

38 Schuyler M, Gott K, Edwards B, et al. Experimental hypersensitivity pneumonitis. Effect of CD4 cell depletion. Am J Respir Crit Care Med 1994; 149: 1286-1294.

39 Turvey SE, Broide DH. Innate immunity. J Allergy Clin Immunol 2010; 125: Suppl. 2, S24-S32. 
40 Watts C, West MA, Zaru R. TLR signalling regulated antigen presentation in dendritic cells. Curr Opin Immunol 2010; 22: 124-130.

41 Girard M, Israel-Assayag E, Cormier Y. Mature CD11c(+) cells are enhanced in hypersensitivity pneumonitis. Eur Respir J 2009; 34: 749-756.

42 Kim YI, Park JE, Brand DD, et al. Protein kinase D1 is essential for the proinflammatory response induced by hypersensitivity pneumonitiscausing thermophilic actinomycetes Saccharopolyspora rectivirgula. J Immunol 2010; 184: 3145-3156.

43 Nance SC, Yi AK, Re FC, et al. MyD88 is necessary for neutrophil recruitment in hypersensitivity pneumonitis. J Leukoc Biol 2008; 83: 1207-1217.

44 Fong DJ, Hogaboam CM, Matsuno Y, et al. Toll-like receptor 6 drives interleukin-17A expression during experimental hypersensitivity pneumonitis. Immunology 2010; 130: 125-136.
45 Heath WR, Carbone FR. Dendritic cell subsets in primary and secondary T cell responses at body surfaces. Nat Immunol 2009; 10: 1237-1244.

46 Shortman K, Naik SH. Steady-state and inflammatory dendriticcell development. Nat Rev Immunol 2007; 7: 19-30.

47 Campbell JD, Cho Y, Foster ML, et al. CpG-containing immunostimulatory DNA sequences elicit TNF- $\alpha$-dependent toxicity in rodents but not in humans. J Clin Invest 2009; 119: 2564-2576.

48 Fink JN. Hypersensitivity pneumonitis. Clin Chest Med 1992; 13 303-309.

49 Scully RE, Mark EJ, McNeely WF, et al. Case records of the Massachusetts General Hospital. Weekly clinicopathological exercises. Case 27-2000. A 61-year-old with rapidly progressive dyspnea. N Engl J Med 2000; 343: 642-649. 